Liz Andréa Kawabata Yoshihara

\title{
Fibrilação atrial e demência: estudo de base populacional no distrito do Butantã, São Paulo
}

Tese apresentada à Faculdade de Medicina da Universidade de São Paulo para obtenção do titulo de Doutor em Ciências

Área de Concentração: Emergências Clinicas

Orientador: Prof. Dr. Paulo Andrade Lotufo

São Paulo

2008 


\section{Dedicatória}

Ao meu Deus, Pai amoroso, meu Porto Seguro, Alicerce de toda a minha vida. O Motivo, a Paz e a Alegria que me norteia e impulsiona a cada passo, porque me sustenta com sua destra fiel.

Aos meus pais, Lyba e Mituo, a quem devo muito mais do que a minha existência. Grandes guerreiros, batalhadores insistentes que, com muito sacrifício, empenho e esforço, nos proporcionaram uma educação de qualidade e, principalmente, a formação e lapidação do nosso caráter. Responsabilidade, perseverança, lealdade, humildade, compaixão e amizade foram valores que nos incutiram desde criança.

Dedico também ao meu amado esposo Carlos, amigo, companheiro, conselheiro, pai exemplar... Compartilhamos tantos momentos de alegrias e vitórias..., também alguns recheados de lágrimas e dor, e a cada dia descubro e aprendo quão maravilhoso é sermos um. Em mim se consolida a certeza de que nossa jornada juntos é bem mais leve do que separados.

Às minhas filhas, Priscila e Lídia, tesouros preciosos que coroam a vida de alegria a cada momento, a cada abraço, a cada sorriso, anjos enviados por Deus que nos fazem acreditar que o mundo ainda pode ser melhor e que ainda devemos batalhar por ele. 


\section{Agradecimentos}

Ao meu orientador, Prof. Dr. Paulo Andrade Lotufo, por ter me aceito como sua orientanda, por sua paciência e dedicação em todos os momentos, mesmo com tantos afazeres e obrigações, mas principalmente na minha formação acadêmica e profissional.

Ao Prof. Dr. Paulo Menezes e a Profa. Dra. Márcia Scazufca, que permitiram que eu trabalhasse no seu projeto, dando um grande estímulo em todas as etapas.

À Profa. Dra. Márcia Martins Silveira Bernik, diretora da Divisão de Clínica Médica, que acreditou em mim, estimulou o meu ingresso no doutorado, e também por sua inestimável amizade e ativa participação no meu desenvolvimento pessoal.

Ao Dr. Aristarcho Whitaker e ao meu irmão Prof. Dr. Vítor Sérgio Kawabata que, com paciência e dedicação, me ajudaram a laudar todos os eletrocardiogramas obtidos, imprescindivel a este trabalho.

À Profa. Dra. Célia Maria Kira e a Profa. Dra. Sandra Gofinet Pasoto, muito mais que amigas, dispensaram o pouco tempo que têm lendo e revisando a versão final da tese.

À Profa. Dra. Isabela Bensenor e ao Prof. Dr. Wong Chiu Ping por me ajudarem na elaboração do "paper" da aula de qualificação.

Às secretárias da Divisão de Clínica Médica do Hospital Universitário, Lourdes e Roberta, sempre solicitas, desde o momento 
da convocação dos pacientes até ouvindo com paciência os meus desabafos nos momentos mais dificeis.

Ás secretárias Rose e Angélica, do Departamento de Emergências Clínicas, "anjinhos da guarda" de todos os pósgraduandos desesperados, sempre atenciosas e dispostas a ajudar em tudo.

A toda equipe do Projeto Idoso, com quem tive excelente convivio, pessoas afáveis, sempre dispostos no possível e no quase impossível também.

Aos técnicos de eletrocardiografia que sempre atenciosos, ajudaram na coleta do material deste protocolo. Em especial o "Chiquinho" que foi no domicílio dos pacientes comigo.

Aos voluntários do hospital que estiveram orientando e tutorando os pacientes idosos pelo nosso hospital.

A Maria Alice Rangel Rebello, bibliotecária do Hospital Universitário, pelo auxílio na bibliografia da tese.

A Iara Rosa da Silva Bustos e sua equipe que forneceram o mapa e os dados da região do Butantã que necessitei.

A minha família de fé que intercedeu, acompanhou e vibrou com cada uma das etapas deste doutorado.

A tantas outras pessoas que de alguma forma me ajudaram com conselhos, "dicas" ou simplesmente com sua presença e amizade. 

Quem nos separará do amor de Cristo? Será tribulação, ou angústia, ou perseguição, ou fome, ou nudez, ou perigo, ou espada? Em todas estas cousas, porém, somos mais que vencedores, por meio daquele que nos amou. Porque eu estou bem certo de que nem morte, nem vida, nem anjos, nem principados, nem cousas do presente, nem do porvir, nem poderes, nem altura, nem profundidade, nem qualquer outra criatura poderá nos separar do amor de Deus, que está em Cristo Jesus

Bíblia Sagrada - Romanos 8:35, 37-39. 


\section{SUMÁRIO:}

\section{Lista de Simbolos}

Lista de Figuras

Lista de Tabelas

Resumo

Summary

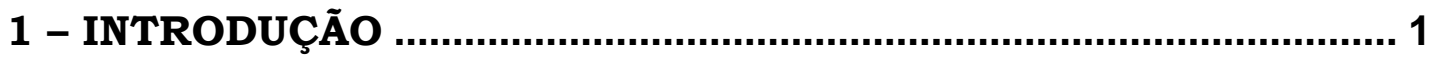

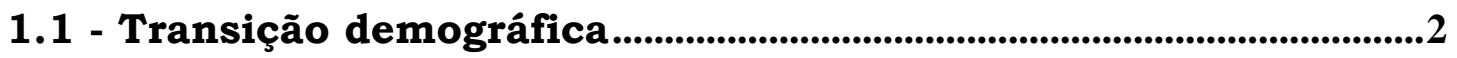

1.2 - Transição epidemiológica ......................................................................4

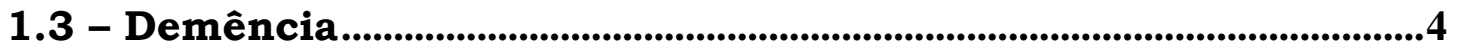

1.4 - Doença cerebrovascular ......................................................................................9

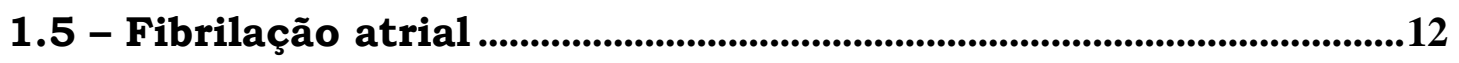

1.6 - Demência e fibrilação atrial................................................................15

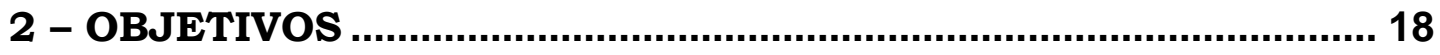

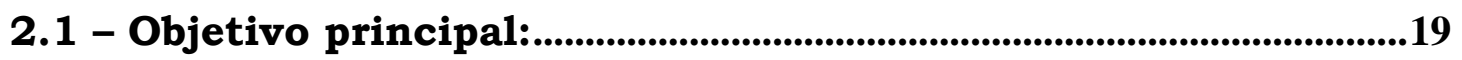

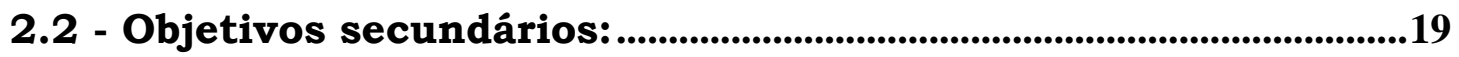

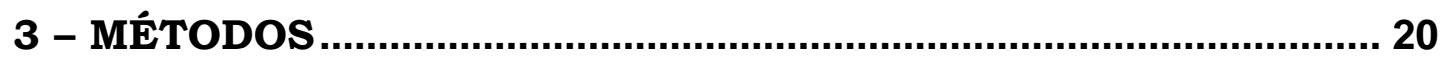

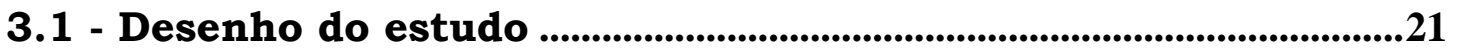

3.2 - Local do estudo e tamanho da amostra ........................................21

3.3 - Considerações éticas .......................................................................................26

3.4 - Procedimentos ....................................................................................27

3.4.1 - Aplicação do questionário de distúrbio cognitivo e demência...................... 27

3.4.2 - Medidas antropométricas e coletas de sangue................................................. 28

3.4.3 - Realização do exame eletrocardiograma de repouso ....................................... 29

3.5 - Diagnóstico de demência ....................................................................29

3.6 - Averiguação da idade ......................................................................................31 
3.7 - Diagnósticos eletrocardiográficos ..................................................32

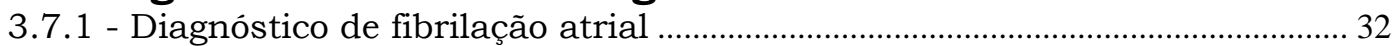

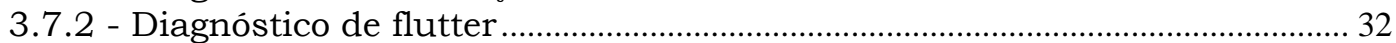

3.7.3 - Diagnóstico de área inativa ao eletrocardiograma ............................................... 33

3.7.4 - Diagnóstico do bloqueio de ramo esquerdo ………………………….................... 33

3.8 - Definição dos fatores de risco cardiovascular..............................34

3.8.1 - Hipertensão arterial sistêmica................................................................. 34

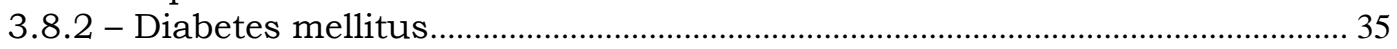

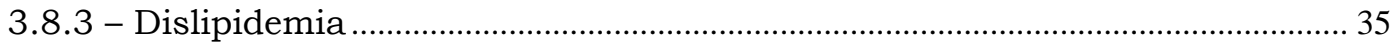

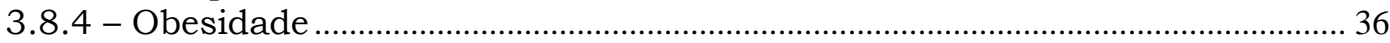

3.9 - Antecedentes mórbidos .....................................................................37

3.10 - Avaliação dos medicamentos utilizados....................................37

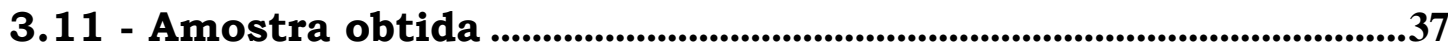

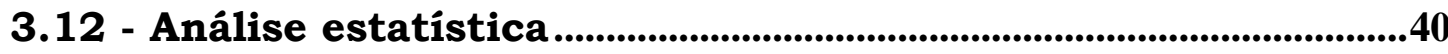

3.13 - Ajustamento da prevalência bruta por idade...............................40

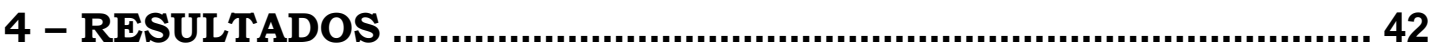

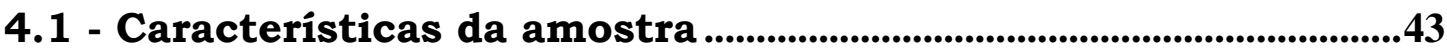

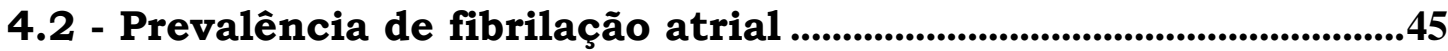

4.3 - Prevalência de demência ...............................................................................55

4.4 - Associação de demência e fibrilação atrial .................................62

4.5 - Outras alterações eletrocardiográficas ......................................66

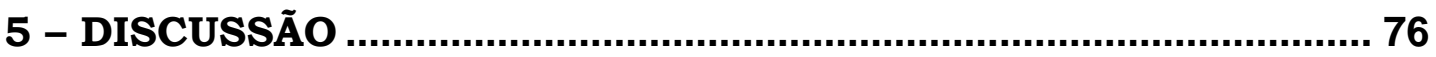

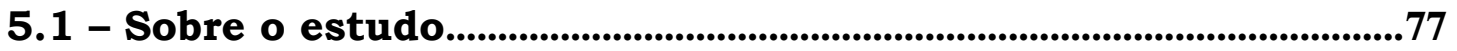

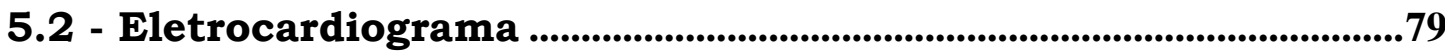

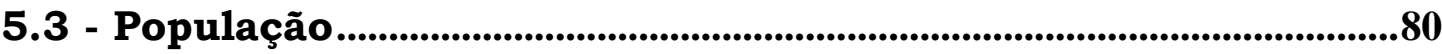

5.4 - Hipertensão arterial............................................................................................80

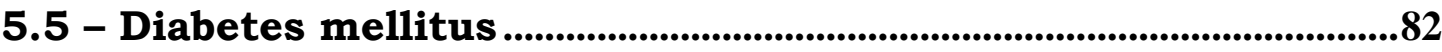

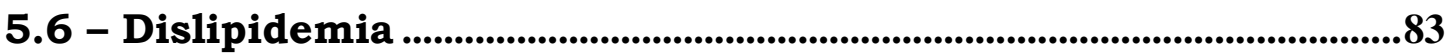

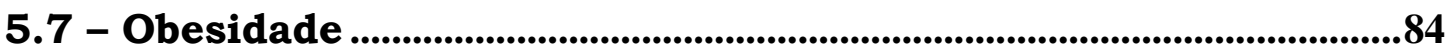

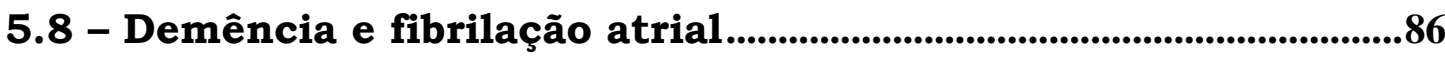


5.9 - Área inativa ao eletrocardiograma ..............................................90

5.10 - Bloqueio de ramo esquerdo .......................................................................91

5.11 - Limitações do estudo ...................................................................................93

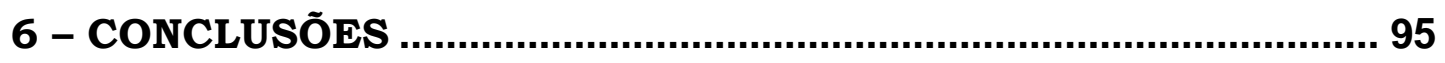

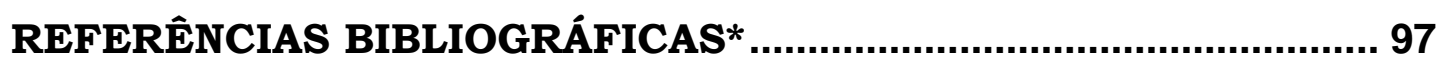

APÊNDICES............................................................................... 110 


\begin{tabular}{|ll}
\hline LISTA DE SÍMBOLOS \\
$\mathrm{kg}$ & quilograma \\
$\mathrm{kg} / \mathrm{m}^{2}$ & quilograma por metro quadrado \\
$\mathrm{m}$ & metro \\
$\mathrm{mg} / \mathrm{dl}$ & miligramas por decilitro \\
$\mathrm{mmHg}$ & milimetros de mercúrio \\
$>$ & maior \\
$=$ & igual \\
$\mathrm{x}$ & vezes \\
+ & mais \\
- & menos \\
\hline
\end{tabular}




\section{TABELAS:}

Tabela 1 - Caracterização da região do Butantã na cidade de São Paulo e seus distritos no ano de 2005

Tabela 2 - Descrição demográfica da amostra de participantes analisa-dos de áreas cobertas pelo Programa Saúde da Família no distrito de saúde do Butantã, São Paulo (SP), em 2005

Tabela 3 - Distribuição dos fatores de risco cardiovascular na amostra de participantes analisados de áreas cobertas pelo Programa Saúde da Família no distrito de saúde do Butantã, São Paulo (SP), em 2005 46

Tabela 4 - Associação de fatores de risco sócio-demográficos e fibrilação atrial na amostra de participantes analisados de áreas cobertas pelo Programa Saúde da Família no distrito de saúde do Butantã, São Paulo (SP), em 2005

Tabela 5 - Associação entre os fatores de risco cardiovascular e fibrilação atrial na amostra de participantes analisados de áreas cobertas pelo Programa Saúde da Família no distrito de saúde do Butantã, São Paulo (SP), em 2005 50

Tabela 6 - Pacientes com fibrilação atrial tratados com medicação antiagregante (ácido acetil salicílico - AAS e ticlopidina) e anticoagulante (varfarina) por sexo e idade na amostra de participantes analisados em áreas cobertas pelo Programa 
Saúde da Família no distrito de saúde do Butantã, São Paulo (SP), em 2005 51

Tabela 7 - Pacientes com fibrilação atrial e que faziam uso de medicação para controle da arritmia ou da freqüência cardíaca na amostra de participantes analisados em áreas cobertas pelo Programa Saúde da Família no distrito de saúde do Butantã, São Paulo (SP), em 2005................... 53

Tabela 8 - História de doenças prévias com fibrilação atrial na amostra de participantes analisados de áreas cobertas pelo Programa Saúde da Família no distrito de saúde do Butantã, São Paulo (SP), em 2005 54

Tabela 9 - Associação de fatores de risco sócio-demográficos e demência na amostra de participantes analisados do Programa Saúde da Família no distrito de saúde do Butantã, São Paulo (SP), em 2005 58

Tabela 10 - Associação entre os fatores de risco cardiovascular e demência na amostra de participantes analisados de áreas cobertas pelo Programa Saúde da Família no distrito de saúde do Butantã, São Paulo (SP), em 2005 60

Tabela 11 - História de doenças prévias com demência na amostra de participantes analisados de áreas cobertas pelo Programa Saúde da Família no distrito de saúde do Butantã, São Paulo (SP), em 2005 
Tabela 12 - Associação entre demência e fibrilação atrial na amostra de participantes analisados de áreas cobertas pelo Programa Saúde da Família no distrito de saúde do Butantã, São Paulo (SP), em 2005 64

Tabela 13 - Razão de chances e intervalo de confiança de 95\% (IC 95\%) para fibrilação atrial e demência ajustado para sexo na amostra de participantes analisados de áreas cobertas pelo Programa Saúde da Família no distrito de saúde do Butantã, São Paulo (SP), em 2005 64

Tabela 14 - Associação entre demência e presença de área inativa ao eletrocardiograma na amostra de participantes analisados de áreas cobertas pelo Programa Saúde da Família no distrito de saúde do Butantã, São Paulo (SP), em 2005 ... 65

Tabela 15 - Associação entre as características sócio-econômicas e onda Q ao ECG na amostra de participantes analisados do Programa Saúde da Família no distrito do Butantã, São Paulo (SP), em 2005 70

Tabela 16 - Associação entre os fatores de risco cardiovascular e áreas inativas ao eletrocardiograma de repouso na amostra de participantes analisados de áreas cobertas pelo Programa Saúde da Família no distrito de saúde do Butantã, São Paulo (SP), em 2005 .......................... 71

Tabela 17 - Fibrilação atrial e áreas inativas no eletrocardiograma por região acometida na amostra de 
participantes analisados de áreas cobertas pelo Programa Saúde da Família no distrito de saúde do Butantã, São Paulo (SP), em 2005 ...................... 72

Tabela 18 - Associação de fatores de risco sócio-demográficos e bloqueio de ramo esquerdo na amostra de participantes do Programa Saúde da Família no distrito do Butantã, São Paulo (SP), em 2005 ........................................... 74

Tabela 19 - Associação entre os fatores de risco cardiovascular e presença de bloqueio de ramo esquerdo na amostra de participantes analisados de áreas cobertas pelo Programa Saúde da Família no distrito de saúde do Butantã, São Paulo (SP), em 2005 75 


\section{FIGURAS:}

Figura 1 - Mapa da cidade de São Paulo, demarcando o distrito do Butantã, com identificação das áreas estudadas 23

Figura 2 - Casuística estudada na população de idosos do distrito de saúde do Butantã - São Paulo 39

Figura 3 - Distribuição da frerqüência de fibrilação atrial por faixa etária e sexo 48

Figura 4 - Distribuição da freqüência de demência por faixa etária e sexo 56

Figura 5 - Distribuição da freqüência de fibrilação atrial e de demência por faixa etária 63

Figura 6- Distribuição da freqüência de área inativa ao eletrocardiograma por faixa etária e sexo 67

Figura 7 - Distribuição da freqüência de onda Q por parede miocárdica acometida por faixa etária 68

Figura 8 - Distribuição da freqüência de bloqueio de ramo esquerdo por faixa etária e sexo 


\section{RESUMO}

Yoshihara LAK. Fibrilação atrial e demência: estudo de base populacional no distrito do Butantã, São Paulo [tese]. São Paulo: Faculdade de Medicina, Universidade de São Paulo; 2008. 111p.

INTRODUÇÃO: O aumento da proporção de idosos implica estudar os determinantes dos principais agravos associados ao envelhecimento como a demência, principalmente a associada à doença cerebrovascular. Um fator de risco relevante para doença cerebrovascular é a freqüência de fibrilação atrial crônica. O São Paulo Health and Ageing Study com base populacional para estudo de distúrbio cognitivo e demência é uma oportunidade única para verificar a prevalência de fibrilação atrial e de sua associação com demência. MÉTODOS: Estudo transversal, por arrolamento de 1524 idosos com 65 anos ou mais estudo acima, no distrito do Butantã, cidade de São Paulo. O diagnóstico de fibrilação atrial foi feito com o eletrocardiograma de repouso de doze derivações e o de demência foi feito utilizando-se o protocolo do "Research Group of Dementia 10/66". Estudaram-se variáveis sócio-econômicas e fatores de risco cardiovascular como hipertensão, diabetes, dislipidemia e obesidade. RESULTADOS: A amostra estudada tinha idade média de 72,2 anos, era predominantemente feminina, branca, casada, de baixa escolaridade e renda. A prevalência de fibrilação atrial associou-se ao aumento da idade e foi de $1,9 \%$ para o sexo feminino e $3,1 \%$ para o sexo masculino, com prevalência para ambos os sexos ajustada para idade de $2,7 \%$. A prevalência de demência também se associou ao aumento da idade e sua prevalência idade ajustada foi de $4,9 \%$, maior em mulheres $(4,8 \%)$ do que em homens $(3,6 \%)$. A razão de chances ajustada para idade para a associação de fibrilação atrial e demência foi de 2,88 (Intervalo de Confiança, IC 95\% - 0,98 - 8,40) para ambos os sexos sendo e, de 1,50 (IC95\% - 0,19 - 11,83) para homens e 4,48 (IC95\% - 1,23 - 16,29) para mulheres. Encontrou-se maior risco de demência entre mulheres com fibrilação atrial $(17,7 \%)$ do que entre os participantes do mesmo sexo sem demência $(4,6 \%)$ Outras alterações no eletrocardiograma de repouso com interesse foram determinadas como com área inativa (código de Minnesotta q1q2) de: $9,1 \%$ nas mulheres e $16,6 \%$ nos homens; e também bloqueio de ramo esquerdo de $3,3 \%$, nas mulheres $3,0 \%$ e nos homens $3,6 \%$. CONCLUSÃO: Mulheres idosas com fibrilação atrial têm diagnóstico de demência quase quatro vezes mais do que aquelas em ritmo sinusal. 


\section{SUMMARY}

Yoshihara LAK. Atrial fibrillation and dementia: a population-based study in the Butantã district, São Paulo [thesis]. São Paulo: "Faculdade de Medicina, Universidade de São Paulo"; 2008. 111p.

INTRODUCTION: The growing aging population proportion makes us study the most important illness related with aging of the population as dementia, specially the dementia associated to stroke. Atrial fibrillation is a main risk factor with cerebrovascular disease. The São Paulo Heath and Ageing Study a population based study for cognitive disturb and dementia is an unique opportunity to verify the atrial fibrillation prevalence and its association with dementia. Methods: This is a cross-sectional study. The population of this study was composed by 1,524 elderly people, over 65 years of age, covered by the Health Program Family in the Butantã district, São Paulo, who were recruited door by door. The diagnosis of atrial fibrillation was made using a twelve lead resting electrocardiogram and the diagnosis of dementia was made by the protocol of Research Group of Dementia $10 / 66$. We studied socio economic variables and cardiovascular risk factors as hypertension, diabetes, dislipidemia and obesity. RESULTS: The studied population had a mean age of 72.2 years old and was predominantly female, white, married and of low educational and financial status. We found that atrial fibrillation prevalence increased throughout age-strata and was of $1.9 \%$ among the females and $3.1 \%$ among the males, and age-adjusted prevalence of $2.7 \%$. The prevalence of dementia also increases with age and its ageadjusted prevalence was of $4.9 \%$, greater among the females $(4.8 \%)$ than among the males (3.6\%). The odds ratio age-adjusted for the association of atrial fibrillations and dementia was of 2.88 (Confidence interval, 95\% CI $-0.98-8.40$ ) for both sex: 1.50 among men $(95 \% \mathrm{CI}-0.19-11.83)$, and 4.48 among women $(95 \% \mathrm{CI}-1.23$ - 16.29). We found a higher risk of dementia among the female with atrial fibrillation $(17.7 \%)$ than among female participants without atrial fibrillation (4.6\%). Other resting electrocardiogram alterations were determined as previous inactive areas (Minnesotta Code q1-q2) of $12.4 \%$ : among the females of $9.1 \%$ and among the males of $16.6 \%$. The frequency of left bundle-branch block was of 3.3\%: among the females of $3.0 \%$ and among the males of $3.6 \%$.CONCLUSION: Elderly women with atrial fibrillation had the diagnosis of dementia almost four times greater than that of women with sinus rhythm.

Key words: atrial fibrillation, prevalence, dementia, elderly. 
1 - Introdução 


\section{1 - Transição demográfica}

Na maioria dos países, observa-se um aumento progressivo da proporção de idosos, com ritmos e em tempos diferenciados. Estimativas da Organização das Nações Unidas prevêem que o número de pessoas em todo o planeta com mais de 60 anos crescerá mais de $300 \%$ nos próximos 50 anos (United Nations, 2007a). Pela primeira vez, de forma inédita, o número de idosos acima de 65 anos suplantará o número de crianças com menos de 15 anos (United Nations, 2007b). Em 2050, um quarto da população da Ásia, Oceania, América Latina, América do Norte e Caribe terão mais de 60 anos. Este índice será de 35\% na Europa e de 10\% na África. A proporção de trabalhadores por pessoas dependentes (menor de 15 ou maior de 65 anos) irá diminuir a partir de 2010 na Europa, Oceania e América do Norte, em 2015 na Ásia e, em 2025, na América Latina e Caribe (United Nations, 2007b).

Haverá também um aumento do número de idosos acima de 80 anos, que aumentará mais de quatro vezes, passando de 88 milhões em 2005 para 402 milhões em 2050. Na América Latina, Ásia e Caribe esse aumento será de seis vezes (United Nations, 2007b). 
Apesar deste envelhecimento populacional ser um fenômeno mundial, no Brasil está acontecendo de forma muito rápida e tem como causa principal a queda da fecundidade. A taxa de fecundidade (em nascidos vivos por mulher entre 15 a 49 anos) era 4,7 em 1970 e de 2,04 em 2004 (United Nations, 2001a; United Nations, 2001b; Brasil, 2006). Esse fenômeno provocou o estreitamento da base da pirâmide etária populacional, que se iniciou em 1960 e se acentuará nos próximos anos. Outros fatores que contribuíram para esta mudança foram a redução da mortalidade infantil e o declínio da mortalidade decorrente das causas cardiovasculares (Lolio et al, 1986). Assim, observa-se um aumento gradativo da expectativa de vida ao nascer e também aos 60 anos (Carvalho et al., 2003).

Em 1950, no Brasil, a população acima de 65 anos correspondia a 3,0\% da população total; em 2000, essa população aumentou $8,6 \%$ e estima-se que, em 2050, corresponderá a $18 \%$ (United Nations, 2007b). Haverá aumento não apenas do número absoluto de idosos, mas principalmente de sua proporção em relação à população total. O envelhecimento populacional, no Brasil, acontece em ritmo bem maior do que em outros países, trazendo consigo implicações sociais em relação ao custo da saúde, às incapacidades resultantes, à concessão dos benefícios previdenciários por períodos prolongados, e ao fato de ocorrer em famílias menores, com dificuldades no cuidar. A perspectiva é que, em 2025, o Brasil 
venha a ser o sexto país do mundo em número de idosos (Ramos et al., 1987).

\section{2 - Transição epidemiológica}

Acompanhando a transição demográfica, observou-se mudança no perfil de mortalidade, com predomínio, desde os anos 40, das doenças cardiovasculares em centros como São Paulo e Rio de Janeiro e, a partir de 1960, em todo país (Lotufo, 2005a). Além da relevância nas estatísticas de mortalidade, as doenças cardiovasculares também são causas importantes de incapacidade nessa faixa etária (World Health Organization, 2001). Entre as doenças cardiovasculares destaca-se, no Brasil, a doença cerebrovascular, com taxas elevadas de mortalidade em comparação a outros países (Lotufo, 2005b). A taxa de mortalidade elevada por doença cerebrovascular permite supor que as conseqüências dos eventos cerebrovasculares também sejam elevadas, como é o caso dos distúrbios cognitivos motores, e em especial, da demência associada à doença cerebrovascular (Veermer et al., 2003).

\section{3 - Demência}

A demência caracteriza-se por um declínio cognitivo progressivo, com acometimento da memória, atenção, pensamento e 
compreensão. Também pode comprometer o humor, a personalidade e o comportamento social, com conseqüente impacto ocupacional e social. Cursa muitas vezes com depressão, agitação e psicose, que dificultam o conviver e o cuidar. Os fatores genéticos e ambientais influenciam na prevalência da demência em diversas regiões do mundo (Scazufca et al., 2002). Entre estes fatores, está a aterosclerose, como mostrado no Cardiovascular Health Study, onde o risco de demência vascular e de doença de Alzheimer foi maior naqueles com outras doenças cardiovasculares, que não o acidente vascular cerebral, como a doença coronariana e, principalmente a doença arterial periférica (Newmann et al., 2005). Além desse rigoroso estudo longitudinal, outros estudos com tempo menor de seguimento ou delineamento não-longitudinal mostraram também associação positiva entre doença cardiovascular e demência (Stewart et al., 1999).

Embora vários estudos de prevalência (sem ajustamento de idade) de demência na população acima de 60 anos mostrem diferença ainda significativa entre Estados Unidos (6,4\%) e América Latina $(4,6 \%)$, a incidência anual prevista por 1000 habitantes é muito mais próxima: 10,5 nos Estados Unidos e 9,2 na América Latina (Ferri et al., 2005). O custo anual de demência nos Estados Unidos em 2005 foi calculado em 76 bilhões; no Japão o custo anual é de 34 bilhões e no mundo todo é de 315 bilhões de dólares (Wimo et 
al, 2007). No Brasil, os custos hospitalares com a doença cerebrovascular aumentaram exponencialmente na população acima de cinqüenta anos (Brasil, 2006).

Além da associação da aterosclerose com demência, há evidências que associam a fibrilação atrial não valvar a acidentes vasculares cerebrais silenciosos e, conseqüentemente, déficits cognitivos (Sabatini et al., 2000; Ott et al., 1997). A causa poderia ser decorrente de fenômenos tromboembólicos, bem como de hipoperfusão associada à arritmia. Sabatini e colaboradores (2000) utilizaram desenho caso-controle para mostrar que, em pacientes internados com idade superior a setenta anos, a presença de fibrilação atrial associava-se a maior declínio cognitivo, quando comparado àqueles com ritmo sinusal.

No Brasil, os estudos se concentram no estado de São Paulo, sendo que dois inquéritos com métodos não comparáveis mostraram valores diferentes. Em Ribeirão Preto (SP), a prevalência de déficit cognitivo e funcional numa população com idade média de 70 anos foi de $18,9 \%$. Houve uma correlação maior desta variável com o aumento da idade, baixa educação formal, história prévia de doença cerebrovascular e epilepsia (Lopes et al., 2007). 
Em Pirajú (SP), a estimativa de demência utilizando os critérios do Diagnostic and Statistical Manual of Mental Disorders, Fourth Edition (DSM-IV), criteria e o Clinical Dementia Rating, em população com idade superior a 65 anos, foi de dois por cento (Ramos-Cerqueira et al., 2005).

Em 1997, foi iniciado em Catanduva (SP) um estudo de prevalência e seguimento de idosos (Herrera et al., 2002) encontrando-se na linha de base uma prevalência de $7,1 \%$ e, na análise multivariada, verificou-se que idades maiores, o sexo feminino e a baixa escolaridade são associados com uma maior prevalência de demência.

Na seqüência desse estudo, um novo exame foi realizado com intervalo médio de quatro anos do primeiro exame. A incidência de demência foi de 13,8 e de doença de Alzheimer foi de 7,7 por 1000 pessoas-ano. A incidência dobrou a cada intervalo qüinqüenal de idade, sem diferença por gênero. Esse estudo mostrou que a incidência no Brasil é comparável a de outros países (Nitrini et al., 2004).

Nesse mesmo estudo, após cinco anos houve 51,3\% de óbitos em pacientes com demência em comparação a $12,7 \%$ entre idosos sem demência. Demência e doença de Alzheimer diminuíram a 
chance de sobrevida com fator igual a cinco. Em análise multivariada, o diagnóstico de demência foi preditor mais importante para a sobrevida do que história pessoal de doença cerebrovascular ou a presença de hipertensão arterial (Nitrini et al., 2005).

O debate entre determinantes genéticos e ambientais ainda é inconclusivo, quando se verificam dois estudos realizados em imigrantes japoneses no Brasil. Em Campo Grande (MS), estudou-se 157 imigrantes de Okinawa com idade superior a 70 anos, com prevalência de $12,1 \%$ para todos os tipos de demência, 5,7\% para doença de Alzheimer, 0,6\% para demência vascular, 4,5\% para demência mista (vascular/ Alzheimer) e 1,3\% para outros tipos de demências. Não houve casos de demência por corpúsculos de Lewy, nem por doença de Pick. Essas taxas foram consideradas elevadas, quando comparadas a de vários estudos realizados no Japão, mas semelhante ao dos países ocidentais (Yamada et al., 2002). Em contraposição, Meguro e colaboradores (2001) compararam a prevalência na cidade de Miyagi no Japão com imigrantes desse local com mais de 65 anos vivendo em quatro cidades da região metropolitana da cidade de São Paulo, utilizando o Cognitive Ability Screening Instrument (CASI) para avaliação. A prevalência de demência de $7,8 \%$ obtida não diferiu daquela observada na cidade de origem. 
Recentemente, publicou-se o resultado de um estudo no distrito do Butantã, na cidade de São Paulo, que deu base a esse projeto. Este estudo com residentes maiores de 65 anos, utilizando o protocolo 10/66 Dementia Research Group, mostrou uma prevalência de demência de $5,1 \%$, a qual aumentou com a idade para ambos os sexos depois dos 75 anos, mas foi estável na faixa dos 65 a 74 anos (Scazufca et al., 2008).

\section{4 - Doença cerebrovascular}

O Brasil tem taxas elevadas de mortalidade por doença cerebrovascular (Lotufo, 2005a) sendo esta, a principal responsável pelas internações hospitalares no país - 28,8\% (Brasil, 2004). A proporção de mortes por doença cerebrovascular é maior entre as mulheres, principalmente as de meia idade, porém a diferença do risco de morte entre os sexos aumenta com a idade, tendo valores maiores nos homens (Lotufo, 2005b) e, na raça negra (Lotufo et al, 2007).

O Framingham Heart Study mostrou que o risco de acidente vascular cerebral aumenta muito, quando ocorre associado a outras doenças: duas vezes na presença de doença aterosclerótica coronariana, três vezes na hipertensão arterial, quatro vezes na insuficiência cardíaca e cinco vezes na fibrilação atrial (Wolf et al., 
1991). O custo estimado direto e indireto de atendimento e tratamento dos casos novos e reincidentes e do tratamento de suas seqüelas é da ordem de 65,5 bilhões de dólares em 2008 (Rosamond et al., 2008). O Framingham Heart Study também mostrou que após seis meses do evento do acidente vascular cerebral isquêmico, em pacientes com mais de 65 anos, a incidência de seqüela foi de (KelleyHayes et al., 2003): - 50\% com hemiparesia; 30\% com dificuldade para deambular sem assistência; 26\% dependentes em suas atividades de vida diária; $19 \%$ com afasia; 35\% com sintomas depressivos e $26 \%$ foram institucionalizados.

Depois de um acidente vascular cerebral, a demência, incluindo a doença de Alzheimer, desenvolve-se em 25\% dos pacientes no periodo de três meses (Desmond et al., 2000). Mesmo após esses três meses e tendo uma avaliação cognitiva normal, ainda há risco de 6 a 9 vezes maior de desenvolver demência no ano subseqüente. Apesar do risco ser maior nos primeiros doze meses após o evento vascular, ele persiste por muitos anos, ou seja, este valor dobra mesmo quando ajustados as variáveis: idade, sexo, grau de instrução, hemisfério de localização ou tipo de acidente vascular cerebral) (Ivan et al., 2004). Por outro lado, em pacientes que apresentam declínio cognitivo ou desenvolvimento de demência foram encontrados novos infartos cerebrais (Wolf et al., 1991). 
No Framingham Heart Study, 37\% dos individuos apresentavam demência mista, sugerindo a combinação de doença vascular no desenvolvimento da doença de Alzheimer (Ivan et al., 2004). A demência após acidente vascular cerebral tem um impacto negativo na sobrevida em longo prazo.

Em estudos de autópsia, em que se encontraram infartos lacunares, os indivíduos tinham maior freqüência de diagnóstico de demência dos que os sem infartos. A maioria dos indivíduos com doença cerebrovascular desenvolve demência vascular ou mista. Desses casos autopsiados, 78\% tinham história ou achado de doença cerebrovascular (Desmond et al., 2000).

Um estudo de sobrevida, avaliando os quadros demenciais após doença cerebrovascular, mostrou que não há diferença entre o tipo de evento - isquêmico ou hemorrágico - mas há com: o aumento da idade, a extensão da área afetada, o acometimento da função renal e a presença de fibrilação atrial (Barba et al., 2000).

Mesmo sem o diagnóstico clínico de demência, a doença cerebrovascular se associou a uma redução das funções cognitivas em aproximadamente um terço de pacientes, quando avaliados três meses após o evento agudo (Tatemichi et al., 1994). 


\section{5 - Fibrilação atrial}

A fibrilação atrial é a arritmia sustentada mais comum e um dos mais importantes problemas emergentes em doença cardiovascular, pelo seu impacto tanto na morbidade como na mortalidade da população. Caracteriza-se pela ausência de onda $\mathrm{P}$ facilmente identificável e pela presença de ondas fibrilatórias rápidas (ondas f), que variam em tamanho, forma, duração e de freqüência irregular variando de 350 a 600 por minuto. A freqüência ventricular é variável de 100 a 160 por minuto.

O flutter atrial é uma arritmia bem menos freqüente, principalmente na forma crônica. Geralmente está associada à cardiopatia estrutural e/ou à doença pulmonar obstrutiva grave. Sua prevalência não é referida, porque é descrito em associação com a fibrilação atrial e também está associado com fenômenos tromboembólicos, talvez por sua coexistência com a fibrilação atrial (Sparks et al., 2001; Fuster et al., 2006).

A prevalência de fibrilação atrial nos Estados Unidos é de 1\%, aumentando de $0,1 \%$ entre adultos com menos de 55 anos para $9 \%$ nos com 80 anos ou mais (Newmann et al., 2005; Go et al., 2001), no sexo masculino (1,5 vezes mais freqüente) (Feinberg et al., 1995) e na 
população caucasiana (Heeringa et al., 2006). Também tem maior incidência nos portadores de insuficiência cardíaca (Fuster et al., 2001). Neste país estima-se que 2,3 milhões de pessoas tenham essa arritmia (Go, 2005). Como a fibrilação atrial aumenta com a idade (Heeringa et al., 2006), estima-se que em 2050 5,6 milhões de pessoas terão esta arritmia (Lloyd-Jones et al., 2004), sendo que, mais de $50 \%$ será entre os indivíduos com mais de 80 anos.

A fibrilação atrial aumenta muito o risco de acidente vascular cerebral (Hart, 2003), sendo responsável por $15-20 \%$ dos acidentes vasculares cerebrais de acordo com Atrial Fibrillation Investigators (1994) e é considerado um fator independente para recorrência (risco de 2,1 ) e recorrência com gravidade (risco de 2,4), se não tratada (Penado et al., 2003). Também está relacionada a um maior risco $(2,23)$ de ficar acamado e dependente (Dulli et al., 2003). Estima-se que 60.000 pessoas por ano têm um acidente vascular cerebral associado à arritmia. Este risco aumenta com a idade. Dos 50 aos 59 anos, o risco é de $1,5 \%$, entre 60 aos 69 anos é de $2,8 \%$, dos 70 aos 79 anos aumenta para $9,9 \%$ e dos 80 aos 89 é de 23,5\% (Wolf et al., 2003).

No Framingham Heart Study, acompanhando pessoas entre 40 a 95 anos, encontrou-se um risco de desenvolver fibrilação atrial de $26 \%$ nos homens e $23 \%$ nas mulheres (Lloyd-Jones et al., 2004). E esse estudo determinou um risco relativo de isquemia cerebral igual a 
cinco na presença de fibrilação atrial. No seguimento de 40 anos, na mesma coorte americana, foi possivel mostrar que a fibrilação atrial dobrou o risco de morrer, mesmo depois de ajustado para doença cardiaca preexistente (Benjamin et al., 1998). A análise das estatísticas vitais nos Estados Unidos revelou que o número de falecidos com fibrilação atrial aumentou de 18.947 em 1980 para 61.946 em 1998, e que a proporção de fibrilação atrial considerada como causa básica do óbito nessa amostra foi um aumento de 8,3\% em 1980 para 11,6\% em 1998. A taxa ajustada para idade (para 100.000 habitantes) aumentou de 27,6 em 1980 para 69,8 em 1998 (aumento anual de 5,4\%). A doença coronariana foi a causa básica mais comum $(26,8 \%)$ como causa de óbito entre os falecidos com fibrilação atrial (Wattigney et al., 2002), mostrando a relação desta com os fatores de risco cardiovascular.

Entre idosos com mais de 80 anos, a fibrilação atrial reduz a sobrevida de 90 dias após evento cerebrovascular (32,8\% comparado a $19,9 \%$ de pacientes sem a arritmia) e aumenta em 50\% a probabilidade de seqüela grave (Lamassa et al., 2001). Em 90\% dos casos embólicos, o trombo acomete o apêndice atrial esquerdo e, os episódios cerebrovasculares que têm esta origem, por formar êmbolos maiores que os de origem valvar, acometem vasos de maior calibre, causando áreas isquêmicas extensas, tendo como conseqüência maiores seqüelas (Hylek et al., 2003). Outra explicação, para a maior 
gravidade do episódio cerebrovascular associado à fibrilação atrial, seria a associação com doença coronariana, que contribuiria com a diminuição do fluxo cerebral para a região isquêmica (Jorgesen et al., 1996). No Copenhagem Heart Study, mostrou-se que $70 \%$ por cento dos pacientes com fibrilação atrial apresentaram isquemias cerebrais letais ou déficits neurológicos importantes; três quartos dos pacientes com fibrilação atrial tornaram-se dependentes em suas atividades de vida diárias comparado a um terço daqueles sem a arritmia (Jorgesen et al., 1996). A proporção de eventos hemisféricos na fibrilação atrial é doze vezes maior do que na doença carotídea. Essa arritmia também se associa a maior freqüência de infartos silenciosos (Ezekowitz et al., 1995) e disfunção cognitiva (Sabatini et al., 2000) provavelmente por microinfartos ou outro mecanismo ainda indeterminado.

\section{6 - Demência e fibrilação atrial}

O Rotterdam Study (Ott et al., 1997) avaliou 6584 idosos, demonstrando maior freqüência de disfunção cognitiva e demência em pacientes com fibrilação atrial. A associação encontrada foi predominante nas mulheres e com idade inferior a 75 anos. A história de acidente vascular cerebral não foi importante nesta associação. 
Um estudo de coorte conduzido por Miyasaka e colaboradores (2007) demonstrou que, após o diagnóstico de fibrilação atrial, existe um aumento do diagnóstico de demência, independente do tipo do acidente vascular cerebral e que a presença desta arritmia, aumenta o risco de mortalidade independente do sexo. No entanto, uma coorte inglesa, CAFE (Cognition in Atrial Fibrillation Evaluation) realizada por Park e colaboradores (2007), não comprovou estes dados, porém tinha alguns viéses como: a idade menor da e a escolaridade maior dos participantes.

A associação de demência com fatores de risco para aterosclerose tem sido mostrada não apenas para a demência vascular, como era de se esperar, mas também para a doença de Alzheimer. Em relação à associação de demência com outros fatores de risco, uma metanálise encontrou que o diabetes está associado a um aumento de 50 a $100 \%$ do risco de desenvolver doença de Alzheimer e outras demências (Biessels et al., 2006). A hipertensão arterial também parece ter correlação, como foi demonstrado no Rotterdam Study (den Heijer et al., 2005), e também em outros estudos (Freitag et al., 2006; Elias et al., 2004). Uma outra metanálise demonstrou aumento do risco com tabagismo (Anstey et al., 2007) e em relação à hipercolesterolemia há dados tanto a favor quanto contra (Casserly e Topol, 2004; Rea et al., 2005). 
Esta tese apresenta os resultados de um estudo transversal delineado para avaliar em população de baixo poder aquisitivo e idosa a associação entre fibrilação atrial e demência, de forma inédita na população brasileira. 
$\underline{2 \text { - OBJETIVOS }}$ 


\section{1 - Objetivo principal:}

Estudar a associação entre fibrilação atrial crônica e demência em idosos de uma população geral, residentes no distrito do Butantã.

\section{2 - Objetivos secundários:}

Determinar:

(1) a prevalência e as características da população com fibrilação atrial e com demência;

(2) os fatores de risco cardiovascular para o aparecimento dessas doenças;

(3) a prevalência de outras alterações eletrocardiográficas relevantes, tais como a de áreas isquêmicas prévias e a do bloqueio completo de ramo esquerdo, suas características populacionais e seus fatores de risco. 
3-MÉTODOS 


\section{1 - Desenho do estudo}

Este é um estudo transversal de base populacional com todos os residentes com idade de 65 anos ou mais, moradores em áreas desfavorecidas economicamente, subdistrito do Butantã, São Paulo, Brasil. Este estudo faz parte de um projeto desenvolvido pelo Grupo de Pesquisa em Demência 10/66 de investigadores internacionais (10/66 Dementia Research Group, 2000), cuja metodologia é apresentada (Apêndice). Os investigadores principais desse estudo são: Márcia Scazufca, Paulo R. Menezes, Homero P. Vallada (Brasil), Juan Libre de Rodriguez (Cuba) e Martin Prince, John Copeland e Paul McKeigue (Reino Unido). Duas publicações recentes (Scazufca, 2007; Scazufca, 2008) mostram com detalhes a metodologia aplicada e os resultados iniciais desse projeto, que, a partir de 2008, passou a ser denominado como São Paulo Ageing \& Health Study.

A presente tese foi financiada com recursos da Fundação de Amparo a Pesquisa do Estado de São Paulo (FAPESP 11915-0/2004) concedido a projeto individual de pesquisa em nome de Paulo Andrade Lotufo.

\section{2 - Local do estudo e tamanho da amostra}


A cidade de São Paulo tem uma área de $1.509 \mathrm{Km}^{2}$ sendo dividida em 96 distritos administrativos (antigos registros de paz), com demarcações territoriais e populacionais. A divisão sanitária da cidade é realizada em cinco coordenadorias (Norte, Sul, Leste, CentroOeste e Sudeste). Cada coordenadoria, por sua vez, é dividida em supervisões de saúde. No caso da coordenadoria centro-oeste há três supervisões: Sé, Lapa-Pinheiros e Butantã. Cada supervisão contém distritos administrativos, no caso do Butantã são cinco distritos: Butantã, Morumbi, Raposo Tavares, Rio Pequeno e Vila Sônia. Em cada distrito há um número variável de unidades básicas de saúde e algumas delas são sedes do Programa de Saúde da Família, de acordo com diretrizes emanadas pelo Ministério da Saúde. A Faculdade de Medicina da Universidade de São Paulo atua na área da supervisão do Butantã, em três unidades básicas de saúde municipais (Jardim São Jorge e Jardim Boa Vista, no distrito Raposo Tavares e Vila Dalva, no distrito Rio Pequeno) além do Centro de Saúde Escola "Samuel Barnsley Pessoa", próprio da Universidade localizado no distrito do Butantã.

Como pode ser observado na Figura 1, a população estudada encontra-se em três distritos administrativos da cidade de São Paulo, supervisão do Butantã: área do distrito de saúde do Butantã, Rio Pequeno e Raposo Tavares, na região oeste da cidade, que apresenta heterogeneidade de acordo com os marcadores sócio-econômicos. 


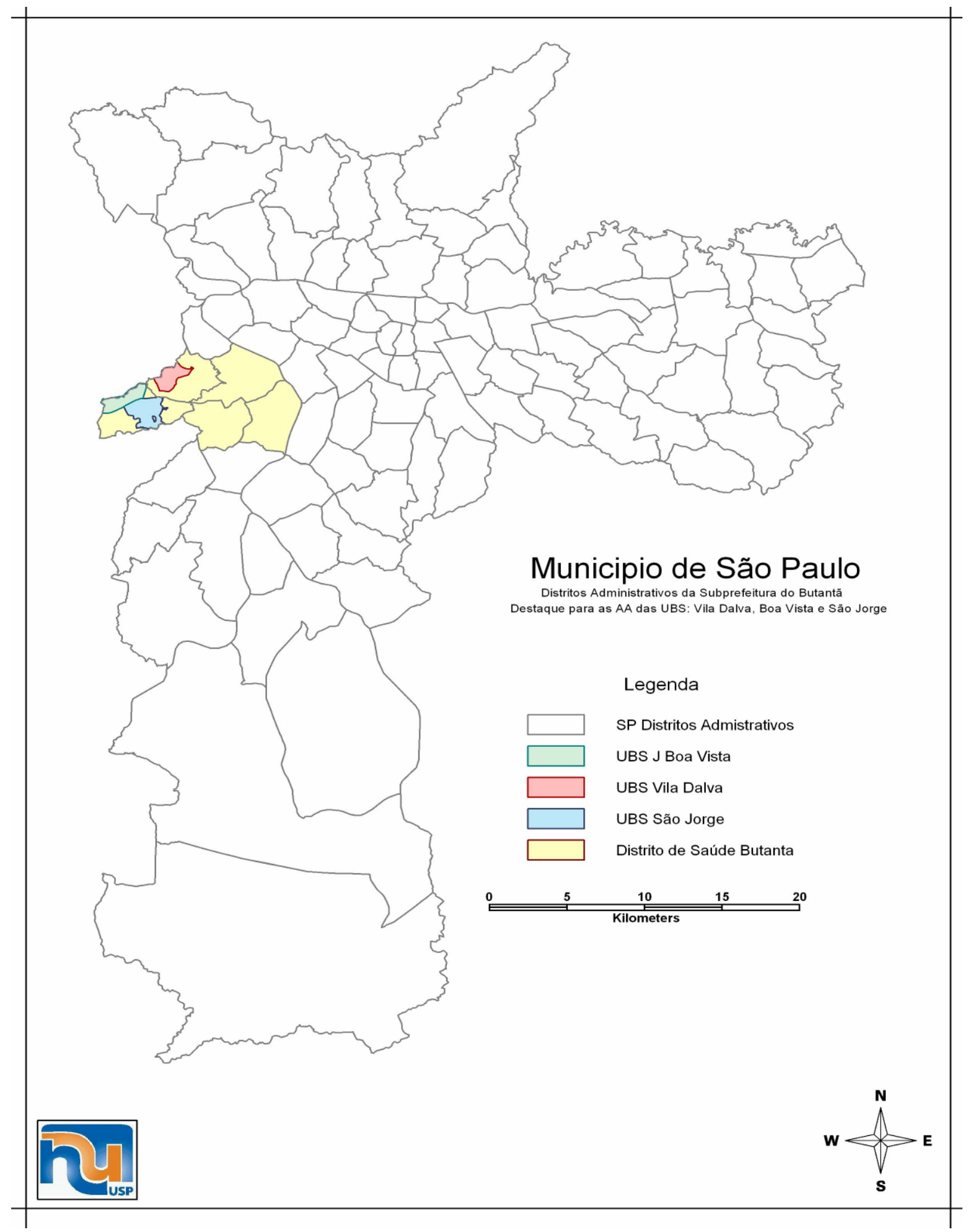

Figura 1 - Mapa da cidade de São Paulo, demarcando o distrito do Butantã, com identificação das áreas estudadas 
Em 2000, a supervisão do Butantã tinha 377.576 moradores $(2,56 \%)$, com 34.690 idosos $(9,2 \%)$ acima de 60 anos. Desta população, $13 \%$ estavam vivendo em favelas, $5 \%$ tinham menos de um ano de escolaridade e 45\% têm mais de 11 anos de instrução. Nos três distritos estudados, as variáveis socioeconômicas (grau de alfabetização, moradia e renda econômica) são apresentadas na Tabela 1.

O estudo foi realizado em 66 setores censitários com uma população aproximada de 63.122 residentes, que representa $16,7 \%$ do total da população da supervisão do Butantã. Esses locais foram escolhidos por serem de regiões atendidas pelo Programa de Saúde da Familia. A escolha desses 66 setores censitários não teve origem no presente estudo, mas sim no estudo-mãe, que necessitava alcançar aproximadamente dois mil participantes com mais de 65 anos para um estudo de distúrbio cognitivo.

Os participantes elegiveis foram todos aqueles que tinham 65 anos de idade ou mais e que moravam nos setores censitários definidos. Eles foram identificados e recrutados em visita sistemática, casa a casa, de todas as famílias desses setores. Indivíduos institucionalizados não foram incluídos. 
Tabela 1 - Caracterização da região do Butantã na cidade de São Paulo e seus distritos no ano de 2005

\begin{tabular}{|c|c|c|c|c|}
\hline & $\begin{array}{l}\text { Supervisão } \\
\text { Butantã }\end{array}$ & $\begin{array}{l}\text { Distrito } \\
\text { Butantã }\end{array}$ & $\begin{array}{l}\text { Distrito R. } \\
\text { Pequeno }\end{array}$ & $\begin{array}{l}\text { Distrito } R \\
\text { Tavares }\end{array}$ \\
\hline Número de moradores & 377.603 & 52.649 & 111.756 & 91.204 \\
\hline Moradores por distrito (\%) & 100,00 & 13,94 & 29,59 & 24,15 \\
\hline Idosos $\geq 60$ anos & 32.064 & 8.148 & 9.272 & 5.020 \\
\hline Idosos $\geq 60$ anos (\%) & 8,49 & 15,47 & 8,29 & 5,50 \\
\hline \multicolumn{5}{|l|}{ Índice de Alfabetização } \\
\hline Maiores de dez anos & 319.592 & 47.313 & 93.455 & 74.645 \\
\hline Maiores de dez anos (\%) & 84,63 & 12,52 & 24,74 & 19,76 \\
\hline Alfabetização > de dez anos & 306.203 & 46.531 & 88.849 & 70.666 \\
\hline Taxa de alfabetização (\%) & 95,81 & 98,35 & 95,07 & 94,67 \\
\hline \multicolumn{5}{|l|}{ Índices Sociais } \\
\hline IDH Distrital* & & 0,72 & 0,47 & 0,48 \\
\hline Ranking IDH Distrital & & 12 & 68 & 66 \\
\hline Numero de favelas & 81 & 5 & 25 & 26 \\
\hline $\begin{array}{l}\text { Residentes de } \\
\text { improvisados }\end{array}$ & 1288 & 78 & 374 & 216 \\
\hline $\begin{array}{l}\text { Residências } \\
\text { improvisadas } \\
\end{array}$ & 383 & 31 & 124 & 56 \\
\hline \multicolumn{5}{|c|}{$\begin{array}{l}\text { Rendimento nominal mensal por } \\
\text { responsável em salários minimos }\end{array}$} \\
\hline Pessoas responsáveis & 106.545 & 16.388 & 31.135 & 24.614 \\
\hline Renda até $1 / 2$ & 142 & 9 & 42 & 47 \\
\hline Renda de $1 / 2$ a 1 & 5.214 & 538 & 1.902 & 1.415 \\
\hline Renda de 1 a 2 & 9.925 & 822 & 3.599 & 2.905 \\
\hline Renda de 2 a 3 & 10.351 & 889 & 3.522 & 3.254 \\
\hline Renda de 3 a 5 & 15.795 & 1.870 & 5.144 & 5.068 \\
\hline Renda de 5 a 10 & 20.465 & 3.442 & 6.363 & 5.336 \\
\hline Renda de 10 a 15 & 7.977 & 1.729 & 2.243 & 1.376 \\
\hline Renda de 15 a 20 & 7.750 & 2.004 & 2.010 & 816 \\
\hline Renda de mais de 20 & 18.900 & 4.075 & 3.532 & 909 \\
\hline Sem rendimento mensal & 10.026 & 1.010 & 2.778 & 3.488 \\
\hline Renda menor que 1 (\%) & 5,02 & 3,33 & 6,24 & 5,93 \\
\hline Renda maior que 15 (\%) & 25,01 & 37,09 & 17,79 & 7,00 \\
\hline
\end{tabular}

* Índice de Desenvolvimento Humano Distrital ou IDH Distrital - adaptação, para o nível dos Distritos Municipais, da fórmula do IDH que é adotada pela ONU, desde 1990.

O IDH é calculado a partir das dimensões de renda (rendimento médio do responsável pelo domicílio), longevidade (com base na mortalidade infantil) e educação.

** Residentes de Improvisados: total de pessoas residentes com domicilios particulares improvisados, como: vagões de trem, carroças, tendas, barracas, trailers, grutas, aqueles situados sob pontes, viadutos etc.

*** Residências Improvisadas: são considerados domicilios particulares improvisados se estiverem servindo de moradia: prédios em construção, vagões de trem, carroças, tendas, barracas, trailers, grutas, aqueles situados sob pontes, viadutos etc. 
A escolha de 66 setores censitários não teve origem no presente estudo, mas sim no estudo-mãe que necessitava alcançar aproximadamente dois mil participantes com mais de 65 anos para estudo de distúrbio cognitivo.

\section{3 - Considerações éticas}

Os participantes foram incluídos somente após a obtenção do termo de consentimento livre e esclarecido assinado (Apêndice). Para os participantes analfabetos os papéis de informação e consentimento foram lidos e eles foram convidados a expressar o seu consentimento verbal, que foi testemunhado por terceiros, não sendo, entretanto solicitado que assinassem um termo que não podiam ler. Foi solicitado que a testemunha assinasse o consentimento informado do participante.

Para as pessoas com quadro de demência, sem capacidade de entender ou consentir, as mesmas foram recrutadas com base na assinatura de concordância dos informantes. Os informantes eram co-residentes próximos dos participantes, parentes ou amigos que conheciam a história do envelhecimento deles.

O estudo recebeu a aprovação ética da Comissão Nacional de Ética em Pesquisa (CONEP-Brasil). 


\section{4 - Procedimentos}

\subsection{1 - Aplicação do questionário de distúrbio cognitivo e demência}

O estudo foi conduzido de maio de 2003 a abril de 2005. Todos os residentes elegiveis com 65 anos de idade ou mais e que aceitaram participar do projeto foram entrevistados. Para cada participante, um informante também foi identificado. A entrevista com os participantes e informantes foram esquematizadas para ocorrerem na residência, aproximadamente uma semana após o recrutamento e, sempre que possivel, realizado simultaneamente por dois diferentes entrevistadores. Todos os participantes foram questionados para demência e quanto às características sócio-econômicas, estilo de vida e fatores de risco cardiovascular. A obtenção de todos esses dados consumia aproximadamente 90 minutos. Os informantes foram questionados sobre habilidades cognitivas e atividades de vida diária dos participantes. Para os participantes com problemas físicos ou mentais graves, os questionamentos sobre as características sócioeconômicas dos participantes foram feitas aos seus informantes.

A equipe de pesquisa foi treinada, em como aplicar o protocolo desenvolvido, durante um mês por oito pesquisadores, que trabalham 
com saúde mental. Na primeira parte do treinamento, eles aprenderam como conduzir o protocolo, avaliar gravações colhidas de indivíduos com demência, depressão e sem nenhuma doença mental e entrevistaram pessoalmente idosos admitidos num hospital geral. Estas atividades foram supervisionadas por um coordenador de estudo e um coordenador de campo. A segunda parte do treinamento consistiu na aplicação do protocolo de estudo em área com uma população semelhante à área de estudo.

Os entrevistadores foram treinados para realizar a abordagem inicial com a população e recrutá-los, e para esquematizar e aplicar o protocolo de estudo em situação real. As entrevistas foram monitoradas no local por dois coordenadores do estudo. Fora do campo, os dados coletados foram discutidos semanalmente.

\subsection{2 - Medidas antropométricas e coletas de sangue}

Após as entrevistas, foram agendados dias para que um auxiliar de enfermagem fosse ao domicilio realizar as medidas de pressão arterial, peso e altura e coletar amostras de sangue para os exames laboratoriais que avaliariam os fatores de risco cardiovascular. 


\subsection{3 - Realização do exame eletrocardiograma de repouso}

Os idosos eram então convidados a comparecer ao Hospital Universitário da Universidade de São Paulo - referência nosocomial do distrito - para a realização do eletrocardiograma de doze derivações, em repouso, no aparelho DIXTAL EP-3. Para os pacientes impossibilitados de comparecer, era agendada uma visita domiciliar para a realização do referido exame.

\section{5 - Diagnóstico de demência}

Para o diagnóstico de demência foi utilizada uma combinação de avaliações estruturadas já existente para o diagnóstico em uma fase, desenvolvida pelo grupo 10/66 (Prince et al., 2003), mostrada a seguir:

a) Avaliação do participante:

- Avaliação do funcionamento cognitivo com os instrumentos "Estado mental geriátrico (Geriatric Mental State; GMS - uma avaliação do Estado Mental) (Copeland et al., 1986);

- O "Instrumento para Rastreamento de Demência na Comunidade" (Community Screening Instrument for Dementia; $C S I-D$ - instrumento com duas partes: um componente para um rastreamento cognitivo breve, e uma história breve com o 
informante sobre o possivel declínio funcional e cognitivo) (Hall et al., 2000);

- Tarefa de aprendizado com a lista de dez palavras, com lembrança tardia (Welsh et al., 1994);

- E, avaliação neurológica estruturada breve com medidas objetivas e quantificáveis de sinais de lateralidade, parkinsonismo, ataxia, apraxia e liberação de reflexos primitivos.

\section{b) Entrevista com o informante:}

- História breve sobre declínio funcional e cognitivo dada pelo informante com o CSI-D (HAS-DDS) e só utilizada se algum declínio é relatado na parte do informante do CSI-D;

- Utilização da "History and Aetiology Schedule Dementia Diagnosis and Subtype (HAS-DDS - avaliação mais detalhada do início e curso da síndrome demencial) (Dewey et al., 2001).

O diagnóstico final de demência foi realizado de duas maneiras. Na primeira abordagem o desfecho principal de demência foi definido como o escore acima de um ponto de corte de probabilidade preditiva $(0,35)$ de síndrome demencial segundo o critério do DSM IV (American Psychiatric Association, 1994), padronizado internacionalmente. É derivado da equação de regressão logística desenvolvida no estudo piloto internacional do grupo 10/66, utilizando coeficientes do GMS, 
CSI-D e teste de 10 palavras. Este é um critério "ético" (validados internacionalmente). A segunda abordagem foi uma validação interna utilizando critérios mais "êmicos" (validados localmente), embora ainda baseados na aplicação local de padrões internacionais; painéis locais de consenso diagnóstico no Brasil e em Cuba aplicaram os critérios operacionais de pesquisa para sindrome demencial segundo o DSM IV e para o diagnóstico dos subtipos de demência: demência de Alzheimer (McKhann et al., 1984), demência vascular (Roman et al., 1993), e demência por corpúsculo de Lewy (McKeith et al., 1992). Os painéis incluíram psiquiatras e neurologistas locais experientes, que revisaram todos os dados disponiveis pertinentes para o diagnóstico e consultaram os entrevistadores quando necessário. A avaliação clínica identificou outras condições prevalentes relevantes para o diagnóstico diferencial de demência e subtipo de demência como psicose, depressão, transtorno ansioso, alcoolismo, epilepsia e acidente vascular cerebral.

\section{6 - Averiguação da idade}

A idade dos participantes foi calculada baseada nos dados do participante e do informante sobre a data de nascimento e coletando informações do documento de identidade deles. Nos casos em que houve inconsistência entre estas fontes, o entrevistador fez outras perguntas e decidiu a idade mais provável do participante. Houve 
incertezas quanto à idade em apenas 39 indivíduos, sendo que em 25 deles, a dúvida se limitou ao máximo em dois anos.

\section{7 - Diagnósticos eletrocardiográficos}

Todos os traçados eletrocardiográficos realizados foram avaliados por dois cardiologistas segundo critérios pré-estabelecidos e descritos abaixo. Nos casos em que houve discordância (5\%), chegouse ao diagnóstico final por consenso entre os avaliadores após discussão presencial.

\subsection{1 - Diagnóstico de fibrilação atrial}

O diagnóstico de fibrilação atrial foi determinado pelos seguintes critérios:

1 - Ausência de onda P (ativação atrial incoordenada);

2 - Presença de onda f (ondas fibrilatórias rápidas que variam em tamanho, forma e duração e de freqüência irregular variando de 350 a 600 por minuto);

3 - Espaços R - R irregulares.

\subsection{2 - Diagnóstico de flutter}


O diagnóstico de flutter foi determinado pelos seguintes critérios:

1 - Presença de ondas $\mathrm{f}$ regulares com freqüência média de 250

a 350 batimentos por minuto;

2 - Onda QRS estreita e rítmica;

3 - Freqüência ventricular de 125 a 175 batimentos por minuto com relação de condução 1:2 ou 1:3.

O flutter e a fibrilação atrial foram contabilizados em conjunto devido ao fato de terem o mesmo comportamento.

\subsection{3 - Diagnóstico de área inativa ao eletrocardiograma}

O diagnóstico de área inativa ao eletrocardiograma foi determinado pelo Código de Minnesota (Prineas et al., 1982), considerando no traçado a presença pelo menos:

1 - Onda Q ou QS em derivação anterior;

2 - Onda Q ou QS em parede posterior (inferior);

3 - Onda Q ou QS em parede antero - lateral.

\subsection{4 - Diagnóstico do bloqueio de ramo esquerdo}

O diagnóstico de bloqueio de ramo esquerdo foi feito da seguinte forma: 
1 - Duração de QRS maior que 0,12 segundos;

2 - Presença de R alargadas ou entalhadas em D1, AVL, V5 e V6;

3 - Ausência de Q em D1, V5 e V6;

4 - Aumento do tempo de ativação ventricular superior a 0,06 segundos em V5 e V6.

\section{8 - Definição dos fatores de risco cardiovascular}

Os fatores de risco cardiovascular clássicos como hipertensão arterial sistêmica, diabetes mellitus, dislipidemia e obesidade foram utilizados na análise de possíveis associações.

\subsection{1 - Hipertensão arterial sistêmica}

A mensuração da pressão arterial foi realizada no domicílio por um auxiliar de enfermagem que efetuou três medidas com intervalo de 2 minutos utilizando um monitor de pressão arterial de braço digital automático (marca OMRON modelo HEM - 712C). A primeira medida foi desprezada.

A hipertensão arterial sistêmica foi definida, segundo os critérios da $V$ Joint National Committee on Detection, Evaluation and Treatment of High Blood Pressure (V JNC, 1993): 
1 - Se o participante apresentou a média da segunda e terceira medidas de pressão arterial: pressão sistólica maior que 140 mmHg, ou pressão diastólica maior que 90 mmHg.

2 - Se o paciente era normotenso (pressão arterial sistólica menor ou igual a $140 \mathrm{mmHg}$ e pressão arterial diastólica menor ou igual a $90 \mathrm{mmHg}$ ), mas fazia uso de medicação antihipertensiva.

\subsection{2 - Diabetes mellitus}

A determinação de diabetes mellitus ocorreu adotando-se os seguintes critérios:

1 - Participante com dosagem de glicemia de jejum maior ou igual a $126 \mathrm{mg} / \mathrm{dl}$, dosado pelo método da hexoquinase na Advia 200 da Bayer.

2 - Participante com glicemia de jejum menor ou igual a 125 $\mathrm{mg} / \mathrm{dl}$, mas em uso de medicações hipoglicemiantes ou insulina.

\subsection{3 - Dislipidemia}

O critério utilizado foi o conteúdo de colesterol da fração Low Density Lipoprotein (LDL) do colesterol, obtido a partir da medida do colesterol total, fração High Density Lipoprotein (HDL) do colesterol e 
triglicérides, utilizando-se a equação de Friedwald (Friedwald et al., 1972) para cálculo: $\mathrm{LDL}=$ colesterol total $-[\mathrm{HDL}$ colesterol $+(0,2 \mathrm{x}$ triglicérides)].

1 - Participante apresentou valores de LDL colesterol maior ou igual a $160 \mathrm{mg} / \mathrm{dl}$, após 12 horas de jejum, medidos pelo método do colesterol oxidase na Advia 200 da Bayer.

2 - Participante apresentou valores de LDL colesterol menor que $160 \mathrm{mg} / \mathrm{dl}$, mas fazia uso de medicações como estatinas (inibidores da HMG-CoA redutase).

\subsection{4 - Obesidade}

A obesidade foi determinada pelo cálculo de Índice de Massa Corpórea (IMC) através da fórmula de Quetelet:

$\mathrm{IMC}=$ Peso $(\mathrm{Kg}) /$ Altura $^{2}(\mathrm{~m})$.

1 - Índice abaixo de $18,5 \mathrm{~kg} / \mathrm{m}^{2}$ é considerado baixo peso.

2 - Índice igual ou maior que 18,5 e menor que $25 \mathrm{~kg} / \mathrm{m}^{2}$ é considerado normal.

3 - Índice igual ou maior que 25 e menor que $30 \mathrm{~kg} / \mathrm{m}^{2}$ é considerado sobrepeso.

4 - Índice igual ou maior que $30 \mathrm{~kg} / \mathrm{m}^{2}$ é considerado obesidade. 


\section{9 - Antecedentes mórbidos}

Questionou-se todos os participantes sobre antecedentes mórbidos de realce como: infarto do miocárdio ou problemas cardiacos, acidente vascular cerebral ou "derrame cerebral", ataque isquêmico transitório ou ameaça de "derrame".

\subsection{0 - Avaliação dos medicamentos utilizados}

Como o questionário foi aplicado em domicílio, houve possibilidade de avaliar os medicamentos em uso pelos participantes, com bastante segurança. O objetivo de registrar os dados das medicações foi de avaliar quantos pacientes com fibrilação atrial estavam recebendo tratamento adequado.

\subsection{1 - Amostra obtida}

Contataram-se 21.727 moradores para alcançar 2266 pessoas com 65 anos de idade ou mais, dos quais 2072 deles $(91,4 \%)$ consentiram participar. Destes, $19(0,8 \%)$ não quiseram realizar o eletrocardiograma, $18(0,8 \%)$ mudaram de endereço depois de cadastrados, $21(0,9 \%)$ faleceram antes da realização do eletrocardiograma, dois $(0,1 \%)$ foram erroneamente inclusos, pois não pertenciam à área delimitada, quatro $(0,1 \%)$ tiveram questionários 
incompletos, com dados que não puderam ser checados, pois não se conseguiu entrevistar os seus familiares, nove $(0,4 \%)$ não puderam ser encontrados, porque estavam trabalhando ou viajando, sem tempo disponivel. Quatrocentos e sessenta e sete $(20,6 \%)$ foram excluídos porque a entrevista tinha sido realizada há mais de um ano, dados que mudariam a avaliação de demência e a de fibrilação atrial. Finalmente, seis $(0,3 \%)$ foram excluídos por serem portadores de marca-passo e três $(0,2 \%)$ por tremores que causavam interferências no traçado eletrocardiográfico, problema técnico insolúvel e, assim, impediram o diagnóstico preciso. O grupo de estudo analisado foi então composto por 1524 (67,2\%) pessoas (Figura 2).

Considerando-se que a prevalência na literatura de fibrilação atrial é de $9 \%$ aos 70 anos e também a distribuição etária da população brasileira no censo de 2000 , a amostra calculada teve a precisão de 1,3 a 1,5, 95\% de confiança. Para demência, utilizando a prevalência de $4,2 \%$, calculamos que nossa amostra teria a precisão de 1,0 a 1,2 , com $95 \%$ de confiança. 


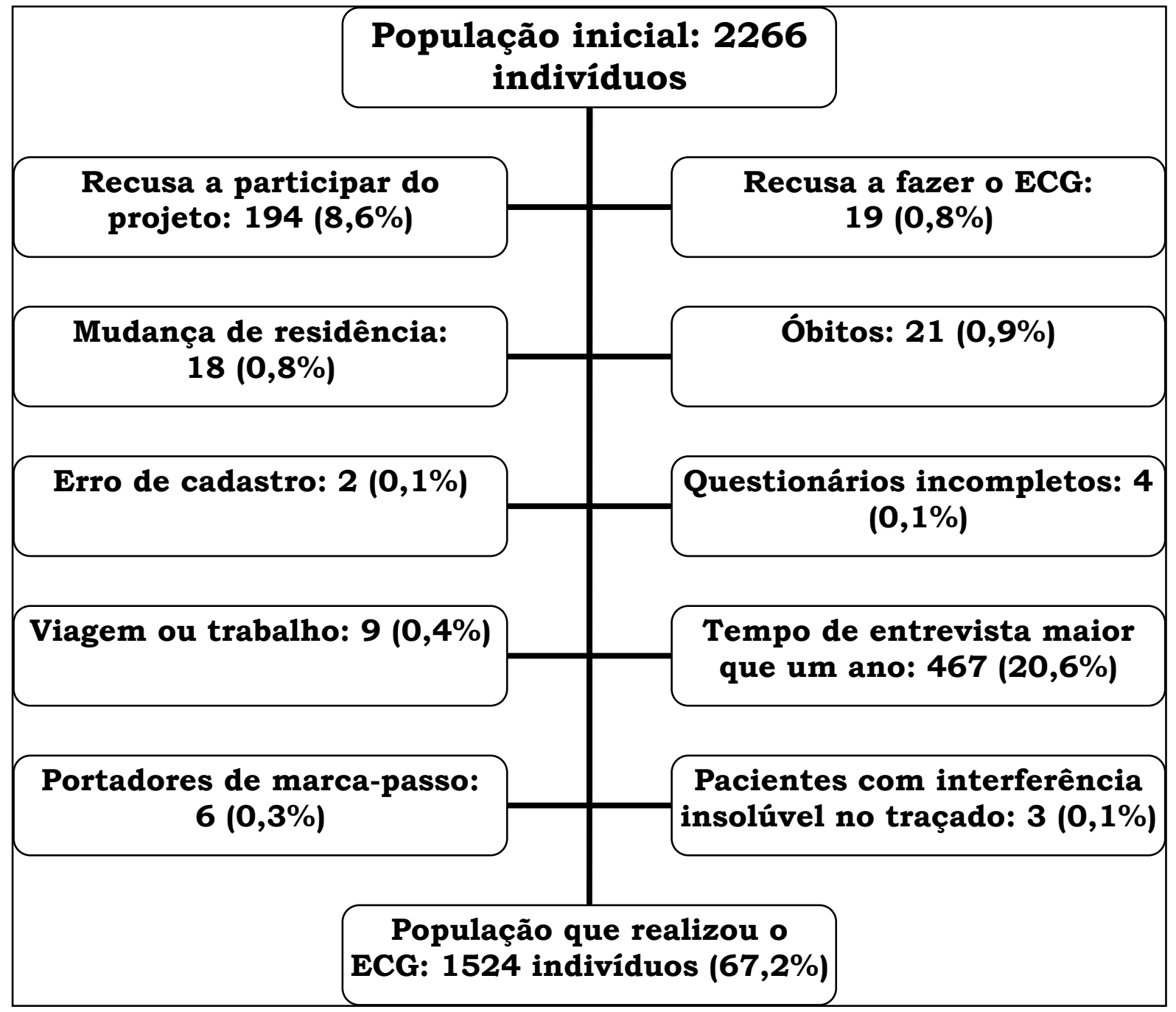

Figura 2 - Casuística estudada na população de idosos do distrito de saúde do Butantã - São Paulo 


\subsection{2 - Análise estatística}

Os dados obtidos foram digitados duas vezes e as diferenças foram conferidas. A idade foi agrupada em quatro faixas etárias de 5 anos cada, exceto a última que engloba os indivíduos com 80 anos ou mais. O nível educacional foi dividido de acordo com anos de escolaridade em três grupos: sem escolaridade, de um a três anos e maior ou igual a quatro. A renda econômica foi dividida em salários mínimos da época.

O banco de dados foi montado no Epidata 3.0, transformado no Stat Transfer e a análise estatística foi feita com o auxílio do Stata 8.0. O cálculo de precisão foi realizado com o auxílio do Epicalc 2000. O Qui-quadrado de Pearson foi utilizado para avaliar os achados eletrocardiográficos e de demência com dados sócio-econômicos e fatores de risco para doença cardiovascular. Para identificar possiveis variáveis de confusão foi utilizada a regressão logística. O valor de $P$ menor que 0,05 foi considerado estatisticamente significativo.

\subsection{3 - Ajustamento da prevalência bruta por idade.}

Este cálculo foi realizado com a população estimada para o distrito do Butantã em 2005, considerando as ponderações decorrentes da proporção em cada sexo da população nas faixas 
etárias de 65 a 69 anos de 0,355; 70 a 74 anos de 0,289; 75 a 79 anos de 0,182 e 80 anos ou mais de 0,174 . 
4 - Resultados 


\section{1 - Caracteristicas da amostra}

As características descritivo-demográficas da população estudada são apresentadas na Tabela 2. A idade variou de 65 a 102 anos (média de 72,2 anos e desvio padrão de 6,3 anos). Quase 70\% estavam na faixa etária de 65-74 anos, sendo $60 \%$ do sexo feminino. Mais de metade dos participantes eram da raça branca. A escolaridade da maior parte da amostra foi inferior a quatro anos de estudo, sendo um terço de analfabetos. A renda mensal aferida foi inferior a três salários mínimos para quase três quartos da população da amostra. Quase um quarto, ainda trabalhava fora e quase metade ainda tinha atividades no domicílio. Quase metade era casada, sendo um terço dos participantes viúvos e, poucos eram solteiros.

As mulheres predominaram em todas as faixas etárias, mas esta diferença tendeu a aumentar com a idade (ver relação feminino/masculino). As mulheres tinham menor escolaridade e menor renda, havia um número maior de analfabetas em relação aos homens. Os homens predominavam tanto como mão-de-obra ativa como inativa e as mulheres predominavam nas atividades domésticas. Havia um número maior de homens casados e menor número de solteiros, viúvos e separados ou divorciados em relação às mulheres. 
Tabela 2 - Descrição demográfica da amostra de participantes analisa-dos de áreas cobertas pelo Programa Saúde da Família no distrito de saúde do Butantã, São Paulo (SP), em 2005.

\begin{tabular}{|c|c|c|c|c|c|}
\hline Característica & $\begin{array}{c}\text { Feminino } \\
N^{1}(\%)\end{array}$ & $\begin{array}{c}\text { Masculino } \\
\mathrm{N}^{2}(\%)\end{array}$ & $\begin{array}{c}\text { População } \\
\text { N (\%) }\end{array}$ & $P$ & Fem/Masc \\
\hline & $915(100,0)$ & $609(100,0)$ & $1524(100,0)$ & & $\begin{array}{c}\mathrm{N}^{1} / 915 / \\
\mathrm{N}^{2} / 609\end{array}$ \\
\hline \multicolumn{6}{|l|}{ Faixa etária (anos) } \\
\hline 65 a 69 & $383(41,9)$ & $279(45,8)$ & $662(43,4)$ & & 0,9 \\
\hline 70 a 74 & $239(26,1)$ & $155(25,5)$ & $394(25,8)$ & & 1,0 \\
\hline 75 a 79 & $171(18,7)$ & $98(16,1)$ & $269(17,7)$ & & 1,2 \\
\hline 80 ou mais & $122(13,3)$ & $77(12,6)$ & $199(13,1)$ & 0,406 & 1,1 \\
\hline \multicolumn{6}{|l|}{ Raça/etnia } \\
\hline Branca & $486(53,1)$ & $318(52,2)$ & $804(52,8)$ & & 1,0 \\
\hline Parda & $270(29,5)$ & $189(31,0)$ & $459(30,1)$ & & 1,0 \\
\hline Negra & $132(14,5)$ & $76(12,5)$ & $208(13,6)$ & & 1,2 \\
\hline Oriental & $23(2,5)$ & $21(3,5)$ & $44(2,9)$ & & 0,7 \\
\hline Outras & $4(0,4)$ & $5(0,8)$ & $9(0,6)$ & 0,507 & 0,5 \\
\hline \multicolumn{6}{|l|}{ Escolaridade (anos) } \\
\hline Analfabetos & $342(37,4)$ & $159(26,1)$ & $501(32,9)$ & & 1,4 \\
\hline $1-3$ anos & $489(53,4)$ & $370(60,8)$ & $859(56,4)$ & & 0,9 \\
\hline 4 anos ou mais & $84(9,2)$ & $80(13,1)$ & $164(10,7)$ & 0,000 & 0,7 \\
\hline \multicolumn{6}{|l|}{ Renda mensal (SM) } \\
\hline Menos de 1 & $131(14,3)$ & $34(5,6)$ & $165(10,8)$ & & 2,6 \\
\hline $1-3$ & $616(67,3)$ & $318(52,2)$ & $934(61,3)$ & & 1,3 \\
\hline $3-5$ & $112(12,2)$ & $139(22,8)$ & $251(16,5)$ & & 0,5 \\
\hline $5-10$ & $50(5,5)$ & $89(14,6)$ & $139(9,1)$ & & 0,4 \\
\hline $10-15$ & $6(0,7)$ & $16(2,7)$ & $22(1,4)$ & & 0,2 \\
\hline $15-20$ & $0(0,0)$ & $13(2,1)$ & $13(0,9)$ & 0,000 & 0,0 \\
\hline \multicolumn{6}{|l|}{ Ocupação } \\
\hline Não trabalha & $57(6,2)$ & $385(63,2)$ & $442(29,0)$ & & 0,1 \\
\hline Trabalha & $145(15,9)$ & $210(34,5)$ & $355(23,3)$ & & 0,5 \\
\hline Dona-de-casa & $713(77,9)$ & $14(2,3)$ & $727(47,7)$ & 0,000 & 33,9 \\
\hline \multicolumn{6}{|l|}{ Estado civil } \\
\hline Solteiro & $49(5,3)$ & $10(1,7)$ & $59(3,9)$ & & 3,3 \\
\hline Casado & $255(27,9)$ & $463(76,0)$ & $718(47,1)$ & & 0,4 \\
\hline Viúvo & $452(49,4)$ & $81(13,3)$ & $533(35,0)$ & & 3,7 \\
\hline Divorciados/separados & $159(17,4)$ & $55(9,0)$ & $214(14,0)$ & 0,000 & 1,9 \\
\hline
\end{tabular}

$\mathrm{N}$ : população total $\mathrm{N} 1$ : população total feminina $\mathrm{N} 2$ : população total masculina 
A Tabela 3 mostra os fatores de risco cardiovascular: três quartos dos participantes eram portadores de hipertensão arterial, metade apresentava sobrepeso, um quarto tinha diagnóstico de diabetes e a mesma proporção apresentava dislipidemia. As mulheres tinham uma maior freqüência de hipertensão arterial, diabetes mellitus e obesidade do que os homens.

\section{2 - Prevalência de fibrilação atrial}

A realização de exames eletrocardiográficos em 1524 participantes revelou 19 homens e 17 mulheres com traçados típicos de fibrilação atrial crônica. A figura 2 mostra a distribuição da freqüência obtida por faixa etária de fibrilação atrial crônica na amostra estudada e evidencia um aumento com a idade. A freqüência em toda amostra foi de $2,4 \%$ sendo de $1,9 \%$ no sexo feminino e $3,1 \%$ no sexo masculino, sem diferença estatisticamente significativa.

A Tabela 4 mostra a associação da fibrilação atrial crônica com as demais variáveis sócio-demográficas. Não houve qualquer associação que indicasse nível de significância apreciável, exceto para as diferentes faixas etárias (Figura 3). 
Tabela 3 - Distribuição dos fatores de risco cardiovascular na amostra de participantes analisados de áreas cobertas pelo Programa Saúde da Família no distrito de saúde do Butantã, São Paulo (SP), em 2005

\begin{tabular}{lccccc}
\hline Fator de risco & $\begin{array}{c}\text { Feminino } \\
\mathrm{N}^{1}(\%)\end{array}$ & $\begin{array}{c}\text { Masculino } \\
\mathrm{N}^{2}(\%)\end{array}$ & $\begin{array}{c}\text { População } \\
\mathrm{N}(\%)\end{array}$ & $P$ & $\begin{array}{c}\mathrm{N}^{1} / 915 / \\
\mathrm{N}^{2} / 609\end{array}$ \\
\hline Hipertensão & $728(79,6)$ & $458(75,2)$ & $1186(77,8)$ & 0,069 & 1,1 \\
\hline Diabetes & $209(22,8)$ & $130(21,3)$ & $339(22,4)$ & 0,494 & 1,1 \\
\hline Dislipidemia & $456(49,8)$ & $293(48,1)$ & $749(49,1)$ & 0,510 & 1,0 \\
\hline IMC $\left(\mathrm{kg} / \mathrm{m}^{2}\right)$ & & & & & \\
\hline$<25,0$ & $371(40,5)$ & $308(50,6)$ & $679(44,2)$ & & 0,8 \\
$25,0-29,9$ & $294(32,1)$ & $232(38,1)$ & $526(34,4)$ & & 0,8 \\
$\geq 30,0$ & $216(23,6)$ & $51(8,4)$ & $267(17,5)$ & 0,000 & 2,8 \\
\hline
\end{tabular}

IMC: índice de massa corpórea $\mathrm{N}$ : população total

N1: população total feminina

N2: população total masculina 
Tabela 4 - Associação de fatores de risco sócio-demográficos e fibrilação atrial na amostra de participantes analisados de áreas cobertas pelo Programa Saúde da Família no distrito de saúde do Butantã, São Paulo (SP), em 2005

\begin{tabular}{|c|c|c|}
\hline Característica & Fibrilação atrial (\%) & $\mathrm{X}^{2}(P)$ \\
\hline \multicolumn{3}{|l|}{ Faixa etária (anos) } \\
\hline 65 a 69 & $5(0,8)$ & \\
\hline 70 a 74 & $10(2,5)$ & \\
\hline 75 a 79 & $8(3,0)$ & \\
\hline 80 ou mais & $13(6,5)$ & $22,91(0,000)$ \\
\hline \multicolumn{3}{|l|}{ Sexo } \\
\hline Feminino & $17(1,9)$ & \\
\hline Masculino & $19(3,1)$ & $2,52(0,112)$ \\
\hline \multicolumn{3}{|l|}{ Raça/etnia } \\
\hline Branca & $21(2,6)$ & \\
\hline Parda & $12(2,6)$ & \\
\hline Negra & $3(1,4)$ & $2,39(0,793)$ \\
\hline \multicolumn{3}{|l|}{ Escolaridade (anos) } \\
\hline Analfabetos & $13(2,6)$ & \\
\hline $1-3$ anos & $22(2,6)$ & \\
\hline 4 anos ou mais & $1(0,6)$ & $2,44(0,294)$ \\
\hline \multicolumn{3}{|l|}{ Renda mensal (SM) } \\
\hline Menos de 1 & $0(0,0)$ & \\
\hline $1-3$ & $31(3,3)$ & \\
\hline $4-5$ & $4(1,6)$ & \\
\hline $6-10$ & $1(0,7)$ & $10,81(0,055)$ \\
\hline \multicolumn{3}{|l|}{ Ocupação } \\
\hline Não trabalha & $16(3,6)$ & \\
\hline Trabalha & $5(1,4)$ & \\
\hline Dona-de-casa & $15(2,1)$ & $4,71(0,095)$ \\
\hline \multicolumn{3}{|l|}{ Estado civil } \\
\hline Solteiro & $2(3,40)$ & \\
\hline Casado & $14(2,00)$ & \\
\hline Viúvo & $14(2,60)$ & \\
\hline Divorciados/separados & $6(2,80)$ & $1,14(0,767)$ \\
\hline
\end{tabular}




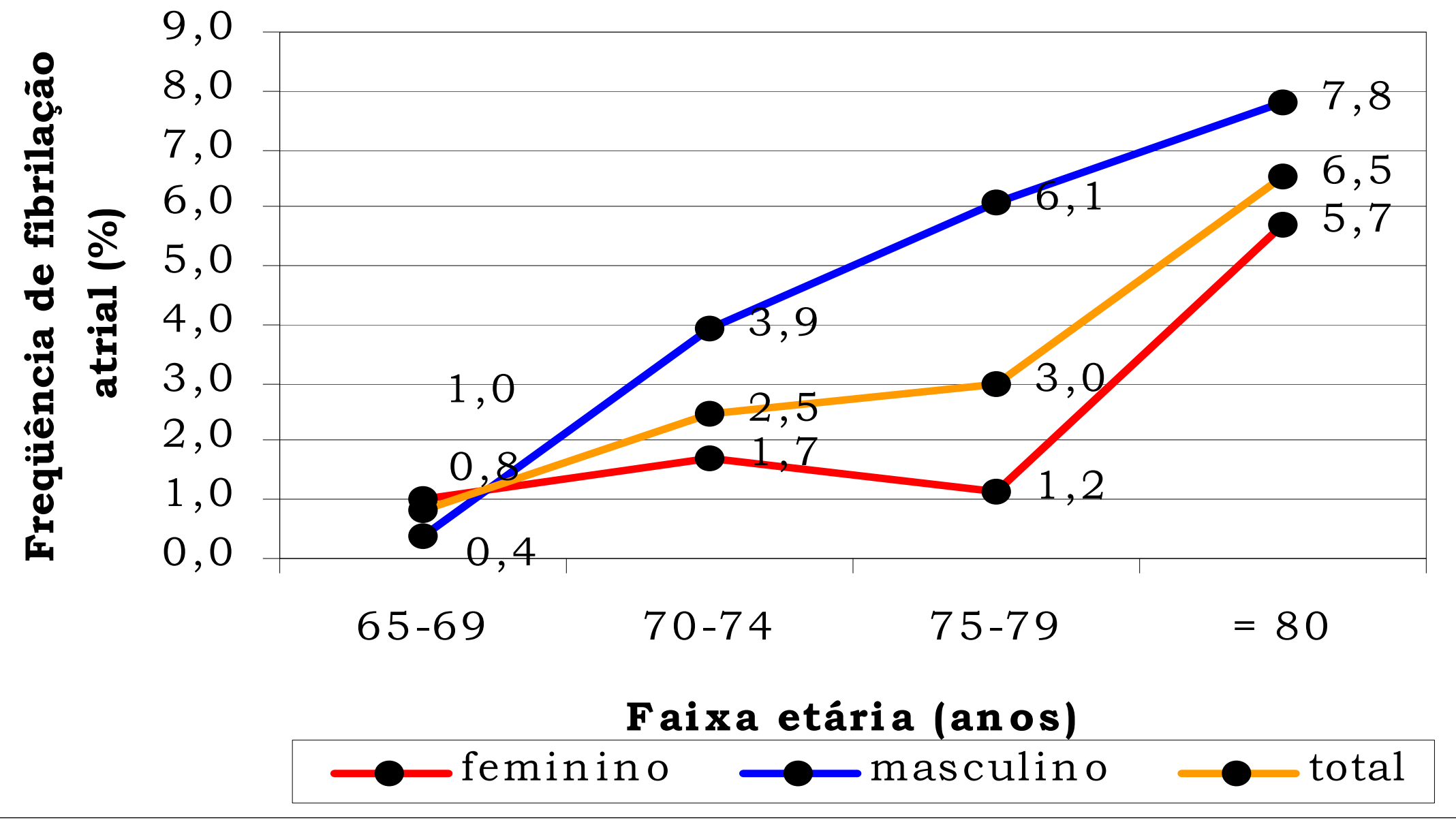

Figura 3 - Distribuição da frerqüência de fibrilação atrial por faixa etária e sexo 
A prevalência ajustada por idade de fibrilação atrial crônica na faixa de 65 anos ou mais foi de 2,7\% (intervalo de confiança de 95\%: $1,9 \%-3,5 \%)$

A associação entre fatores de risco cardiovascular e presença de fibrilação atrial foi testada com hipertensão arterial, diabetes mellitus, dislipidemia e obesidade, tal como apresentado na Tabela 5. Não houve diferença significativa para a associação com hipertensão arterial, de diabetes mellitus ou de dislipidemia individualmente. Entretanto, observou-se uma associação inversa entre níveis de obesidade e fibrilação atrial crônica.

A freqüência bruta não ajustada por idade de fibrilação atrial não foi estatisticamente significativa para hipertensão arterial, diabetes mellitus e dislipidemia. Em relação ao índice de massa corpórea, a freqüência de fibrilação atrial diminui com o aumento deste, sendo de 3,0\% para não obesos, $2,3 \%$ para os com sobrepeso e 1,5\% para os obesos, porém sem significância estatística.

$\mathrm{Na}$ Tabela 6 analisa-se as medicações utilizadas pelos pacientes com fibrilação atrial. 
Tabela 5 - Associação entre os fatores de risco cardiovascular e fibrilação atrial na amostra de participantes analisados de áreas cobertas pelo Programa Saúde da Família no distrito de saúde do Butantã, São Paulo (SP), em 2005

\begin{tabular}{lcc}
\hline Fator de risco & Fibrilação atrial $(\%)$ & $X^{2}(P)$ \\
\hline Hipertensão & & \\
\hline Sim & $29(2,5)$ & $0,05(0,824)$ \\
Não & $7(2,2)$ & \\
\hline Diabetes & & $0,01(0,907)$ \\
\hline Sim & $8(2,4)$ & \\
Não & $28(2,5)$ & \\
\hline Dislipidemia & & \\
\hline Sim & $17(2,3)$ & \\
Não & $19(2,5)$ & \\
\hline IMC $\left(\mathrm{kg} / \mathrm{m}^{2}\right)$ & & $1,78(0,412)$ \\
\hline$<25,0$ & $20(3,0)$ & \\
$25,0-29,9$ & $12(2,3)$ & \\
$\geq 30,0$ & $4(1,5)$ & \\
\hline
\end{tabular}


Tabela 6 - Pacientes com fibrilação atrial tratados com medicação antiagregante (ácido acetil salicílico - AAS e ticlopidina) e anticoagulante (varfarina) por sexo e idade na amostra de participantes analisados em áreas cobertas pelo Programa Saúde da Família no distrito de saúde do Butantã, São Paulo (SP), em 2005

\begin{tabular}{|c|c|c|c|c|c|c|}
\hline & Varfarina & AAS & Ticlopidina & Total medicados & Total de fibrilação atrial & $\%$ com tratamento \\
\hline Feminino & $3(17,6)$ & $5(29,4)$ & 0 & 8 & 17 & 47,1 \\
\hline Masculino & $5(26,3)$ & $4(21,1)$ & $1(10,0)$ & 10 & 19 & 52,7 \\
\hline \multirow[t]{2}{*}{ Total } & $8(22,2)$ & $9(25,0)$ & $1(2,8)$ & 18 & 36 & 50,0 \\
\hline & Varfarina & AAS & Ticlopidina & Total medicados & Total de fibrilação atrial & $\%$ com tratamento \\
\hline $65-69$ & $2(40,0)$ & $1(20,0)$ & 0 & 3 & 5 & 60,0 \\
\hline $70-74$ & $2(20,0)$ & $3(30,0)$ & 0 & 5 & 10 & 50,0 \\
\hline $75-79$ & $2(25,0)$ & $2(25,0)$ & $1(10,0)$ & 5 & 8 & 62,5 \\
\hline$\geq 80$ & $2(15,4)$ & $3(23,1)$ & 0 & 5 & 13 & 38,5 \\
\hline Total & $8(22,2)$ & $9(25,0)$ & $1(2,8)$ & 18 & 36 & 50,0 \\
\hline
\end{tabular}


Apenas $50 \%$ dos pacientes com fibrilação atrial faziam uso de medicação preventiva para tromboembolismo (varfarina, ácido acetil salicílico (AAS) ou ticlopidina) e, conseqüentemente para o acidente vascular cerebral. É possivel identificar que não há variação quanto ao sexo, mas em relação à idade verificou-se que existe uma tendência menor de usar varfarina em indivíduos mais idosos, porém sem significância estatística.

Na Tabela 7 encontramos as medicações indicadas para o controle da freqüência cardiaca nestes indivíduos.

Dos 1488 indivíduos que não apresentavam fibrilação atrial, 25 deles $(1,7 \%)$ usavam amiodarona e três $(0,2 \%)$ usavam propafenona, mesmo não tendo arritmia detectável.

Destes dados, é possivel inferir que 17 indivíduos $(47,2 \%)$ faziam uso de digoxina, beta bloqueadores ou bloqueadores de canal de cálcio, ou seja, usavam medicação para controlar a freqüência cardíaca.

Na Tabela 8 encontramos a relação de histórias prévias de doenças cardíacas, acidente vascular cerebral e episódio isquêmico transitório em relação à fibrilação atrial. 
Tabela 7 - Pacientes com fibrilação atrial e que faziam uso de medicação para controle da arritmia ou da freqüência cardiaca na amostra de participantes analisados em áreas cobertas pelo Programa Saúde da Família no distrito de saúde do Butantã, São Paulo (SP), em 2005

\begin{tabular}{|c|c|c|c|c|c|c|c|}
\hline & Amiodarona & Digoxina & $\beta$ bloqueador & Bloqueador cálcio & Total medicados & $\begin{array}{c}\text { Total de fibrilação } \\
\text { atrial }\end{array}$ & $\begin{array}{c}\% \text { com } \\
\text { tratamento }\end{array}$ \\
\hline Feminino & 0 & $4(23,5)$ & $2(11,8)$ & $2(11,8)$ & 8 & 17 & 47,1 \\
\hline Masculino & $2(10,5)$ & $6(31,6)$ & $1(5,3)$ & 0 & 9 & 19 & 47,4 \\
\hline \multirow[t]{2}{*}{ Total } & $2(5,6)$ & $10(27,8)$ & $3(8,3)$ & $2(5,6)$ & 17 & 36 & 47,2 \\
\hline & Amiodarona & Digoxina & $\beta$ bloqueador & Bloqueador cálcio & Total medicados & $\begin{array}{c}\text { Total de fibrilação } \\
\text { atrial }\end{array}$ & $\begin{array}{c}\% \text { com } \\
\text { tratamento }\end{array}$ \\
\hline $65-69$ & 0 & $2(40,0)$ & 0 & 0 & 2 & 5 & 40,0 \\
\hline $70-74$ & 0 & $3(30,0)$ & 0 & $1(10,0)$ & 4 & 10 & 40,0 \\
\hline $75-79$ & $1(12,5)$ & $2(25,0)$ & $1(12,5)$ & 0 & 4 & 8 & 50,0 \\
\hline$\geq 80$ & $1(7,7)$ & $3(23,1)$ & $2(15,4)$ & $1(7,7)$ & 7 & 13 & 53,8 \\
\hline Total & $2(5,6)$ & $10(27,8)$ & $3(8,3)$ & $2(5,6)$ & 17 & 36 & 47,2 \\
\hline
\end{tabular}


Tabela 8 - História de doenças prévias com fibrilação atrial na amostra de participantes analisados de áreas cobertas pelo Programa Saúde da Família no distrito de saúde do Butantã, São Paulo (SP), em 2005

\begin{tabular}{lcc}
\hline & Fibrilação atrial $(\%)$ & $\mathrm{X}^{2}(P)$ \\
\hline Problema cardiaco & & \\
\hline Com diagnóstico & $23(6,1)$ & $30,67(0,000)$ \\
\hline Sem diagnóstico & $13(1,1)$ & \\
\hline Acidente vascular cerebral & & $0,94(0,331)$ \\
\hline Com diagnóstico & $5(3,6)$ & \\
\hline Sem diagnóstico & $31(2,2)$ & \\
\hline Episódio isquêmico transitório & & $7,95(0,005)$ \\
\hline Com diagnóstico & $4(8,5)$ & \\
Sem diagnóstico & $32(2,2)$ & \\
\hline
\end{tabular}


O antecedente de doença cardíaca e de episódio isquêmico transitório mostraram correlação positiva com a presença de fibrilação atrial $(P=0,000$ e $P=0,005$, respectivamente) . História prévia de acidente vascular cerebral, entretanto, não mostrou correlação positiva com fibrilação atrial nesta população.

\section{3 - Prevalência de demência}

A freqüência de demência (Figura 4) aumentou com a idade, atingindo 7,0\% na faixa etária de 75-79 anos e 15\% na faixa etária de 80 anos ou mais.

Na nossa amostra, foram identificados 66 casos de demência, sendo 44 em mulheres $(4,4 \%)$ e 22 em homens $(3,6 \%)$, sem diferença significativa $(P=0,290)$. Desses 66 casos, 23 deles $(1,5 \%)$ foram consideradas causadas por doença de Alzheimer, 22 (1,4\%) de origem vascular isquêmica, $16(1,1 \%)$ demência mista (Alzheimer e vascular) e $5(0,3 \%)$ demência por doença de Parkinson. Foram identificados apenas quatro participantes com ambas as condições, fibrilação atrial e demência, sendo dois casos com Alzheimer, um vascular e um misto. 


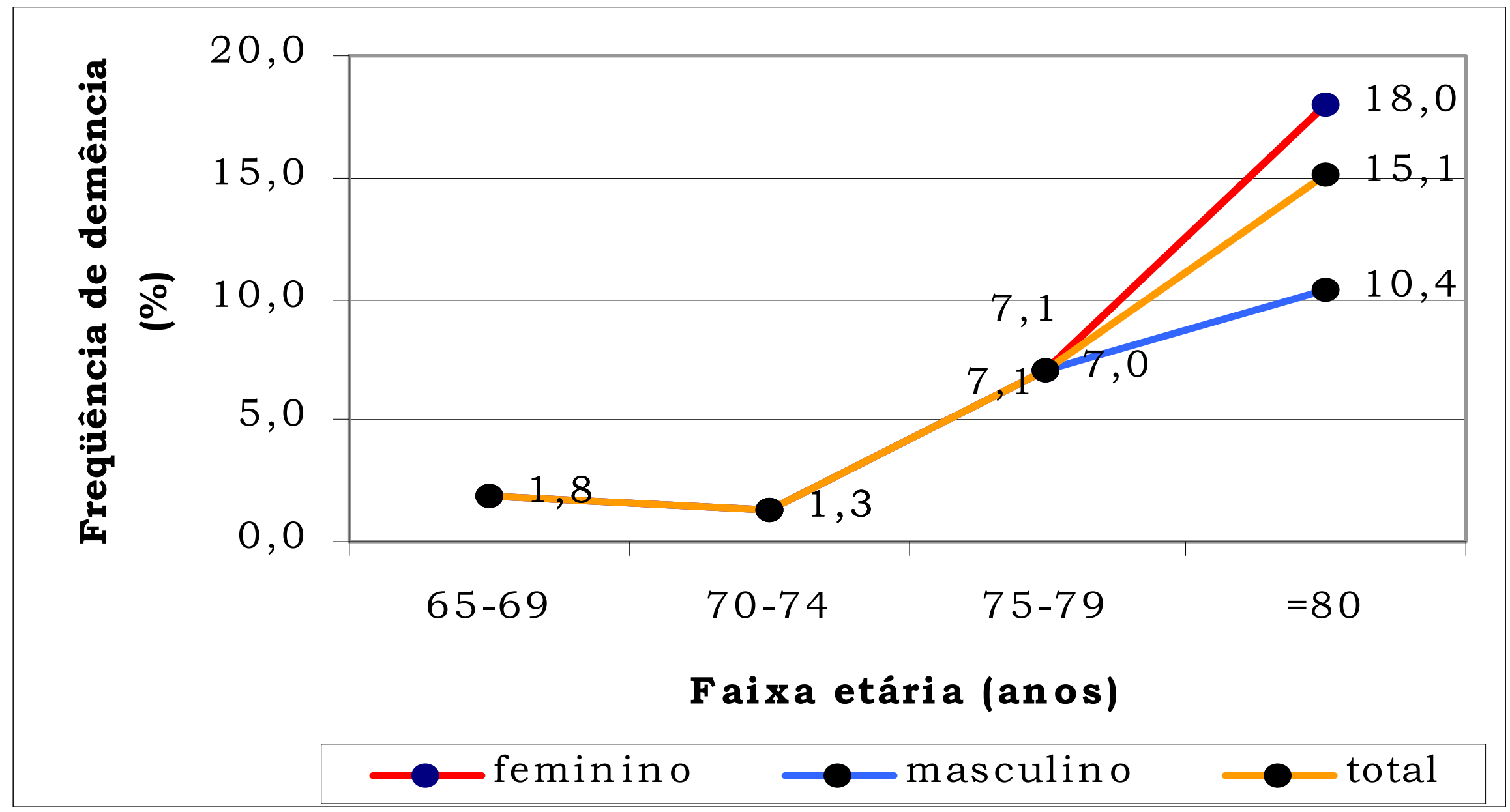

Figura 4 - Distribuição da freqüência de demência por faixa etária e sexo 
A distribuição da freqüência de demência em relação ao sexo, praticamente se sobrepõe até a faixa etária de 75-79 anos, quando então há um aumento no sexo feminino, mas sem significância estatística. A prevalência ajustada de demência por idade encontrada foi de $4,9 \%$ com intervalo de confiança de $95 \%$ de $3,8 \%-6,0 \%$.

A demência foi mais prevalente entre os participantes de baixa escolaridade: $6,8 \%$ entre analfabetos, $3,7 \%$ naqueles com um a três anos de escolaridade e zero por cento entre os de maior escolaridade (Tabela 9).

O diagnóstico de demência foi mais presente entre os indivíduos de baixa renda - menos de cinco salários mínimos e teve relação direta com o trabalho externo, porque a demência impossibilita esta atividade. Além disso, os que viviam sozinhos (solteiros, viúvos e divorciados/separados) tiveram freqüência de demência de $6,1 \%$ em relação a $2,4 \%$ no grupo de casados; e são justamente esses indivíduos solitários que apresentam maior dificuldade de suporte familiar, sem a figura do cônjuge. 
Tabela 9 - Associação de fatores de risco sócio-demográficos e demência na amostra de participantes analisados do Programa Saúde da Família no distrito de saúde do Butantã, São Paulo (SP), em 2005

\begin{tabular}{|c|c|c|}
\hline Característica & Demência (\%) & $\mathrm{X}^{2}(P)$ \\
\hline \multicolumn{3}{|l|}{ Faixa etária (anos) } \\
\hline 65 a 69 & $12(1,8)$ & \\
\hline 70 a 74 & $5(1,3)$ & \\
\hline 75 a 79 & $19(7,0)$ & \\
\hline 80 ou mais & $30(15,1)$ & $79,34(0,000)$ \\
\hline \multicolumn{3}{|l|}{ Sexo } \\
\hline Feminino & $44(4,8)$ & \\
\hline Masculino & $22(3,6)$ & $1,26(0,261)$ \\
\hline \multicolumn{3}{|l|}{ Raça/etnia } \\
\hline Branca & $27(3,4)$ & \\
\hline Parda & $25(5,4)$ & \\
\hline Negra & $11(5,3)$ & \\
\hline Oriental & $2(4,5)$ & \\
\hline Outras & $1(12,5)$ & $5,01(0,414)$ \\
\hline \multicolumn{3}{|l|}{ Escolaridade (anos) } \\
\hline Analfabetos & $34(6,8)$ & \\
\hline $1-3$ anos & $32(3,7)$ & \\
\hline 4 anos ou mais & $0(0,0)$ & $15,48(0,000)$ \\
\hline \multicolumn{3}{|l|}{ Renda mensal (SM) } \\
\hline Menos de 1 & $9(5,5)$ & \\
\hline $1-3$ & $49(5,3)$ & \\
\hline $4-5$ & $7(2,8)$ & \\
\hline $6-10$ & $1(0,7)$ & \\
\hline $11-20$ & $0(0,0)$ & $9,79(0,081)$ \\
\hline \multicolumn{3}{|l|}{ Ocupação } \\
\hline Não trabalha & $39(8,8)$ & \\
\hline Trabalha & $1(0,3)$ & \\
\hline Dona-de-casa & $26(3,6)$ & $36,58(0,000)$ \\
\hline \multicolumn{3}{|l|}{ Estado civil } \\
\hline Solteiro & $4(6,8)$ & \\
\hline Casado & $17(2,4)$ & \\
\hline Viúvo & $37(6,9)$ & \\
\hline Divorciados/separados & $8(3,7)$ & $16,48(0,001)$ \\
\hline
\end{tabular}


A associação com os fatores de risco cardiovascular é apresentada na Tabela 10. Indivíduos com índice de massa corpórea (IMC) mais elevado apresentaram uma freqüência menor de demência $(1,5 \%)$, quando comparados com indivíduos com IMC normal ou baixo $(7,1 \%$ de demência). Observou-se uma relação inversa entre demência e aumento de IMC, cuja explicação seria um exemplo típico de causação inversa, o quadro demencial propiciando a depauperação nutricional.

A Tabela 11 correlaciona os dados de demência com a história de doenças prévias. História de acidente vascular cerebral correlacionou-se positivamente com demência. Não houve correlação com história cardíaca prévia e episódio isquêmico transitório.

Metade dos pacientes com diagnóstico de demência vascular ou mista tinham diagnóstico de acidente vascular cerebral prévio e uma porcentagem bem menor $(5,3 \%)$ tinha diagnóstico prévio de ataque isquêmico transitório. Já dos indivíduos com doença de Alzheimer, apenas $4,4 \%$ tinha diagnóstico prévio de acidente vascular cerebral. Diagnóstico de acidente vascular cerebral sem diagnóstico de demência foi encontrado em 121 indivíduos da população estudada $(8,3 \%)$ 
Tabela 10 - Associação entre os fatores de risco cardiovascular e demência na amostra de participantes analisados de áreas cobertas pelo Programa Saúde da Família no distrito de saúde do Butantã, São Paulo (SP), em 2005

\begin{tabular}{lcc}
\hline Fator de risco & Demência $(\%)$ & $\mathrm{X}^{2}(P)$ \\
\hline Hipertensão & & \\
\hline Sim & $54(4,6)$ & $1,76(0,185)$ \\
Não & $9(2,9)$ & \\
\hline Diabetes & $14(4,1)$ & $0,02(0,876)$ \\
\hline Sim & $49(4,3)$ & \\
Não & & $0,42(0,519)$ \\
\hline Dislipidemia & $35(4,7)$ & \\
\hline Sim & $31(4,0)$ & \\
Não & & $25,57(0,000)$ \\
\hline IMC $\left(\mathrm{kg} / \mathrm{m}^{2}\right)$ & $48(7,1)$ & \\
$<25,0$ & $10(1,9)$ & \\
$25,0-29,9$ & $4(1,5)$ & \\
$\geq 30,0$ & &
\end{tabular}


Tabela 11 - História de doenças prévias com demência na amostra de participantes analisados de áreas cobertas pelo Programa Saúde da Família no distrito de saúde do Butantã, São Paulo (SP), em 2005

\begin{tabular}{lcc}
\hline & Demência (\%) & $\mathrm{X}^{2}(P)$ \\
\hline Problema cardiaco & & \\
\hline Com diagnóstico & $54(4,7)$ & $1,53(0,215)$ \\
\hline Sem diagnóstico & & \\
\hline Acidente vascular cerebral & $20(14,2)$ & $36,41(0,000)$ \\
\hline Com diagnóstico & $46(3,3)$ & \\
Sem diagnóstico & & $0,00(0,979)$ \\
\hline Episódio isquêmico transitório & $2(4,3)$ & \\
\hline Com diagnóstico & $64(4,3)$ & \\
Sem diagnóstico & & \\
\hline
\end{tabular}




\section{4 - Associação de demência e fibrilação atrial}

A Figura 5 mostra a freqüência obtida de demência na população estudada por faixa etária comparada com a freqüência de fibrilação atrial crônica para mostrar a importância da idade na análise das duas situações.

A associação de demência e fibrilação atrial foi analisada por sexo na Tabela 12 .

Na população masculina não houve diferença significativa. No entanto, entre as mulheres com demência, a fibrilação atrial foi encontrada em três dos casos $(17,7 \%)$, quando comparado ao grupo sem diagnóstico de demência com 41 (4,6\%), $P=0,013$. 


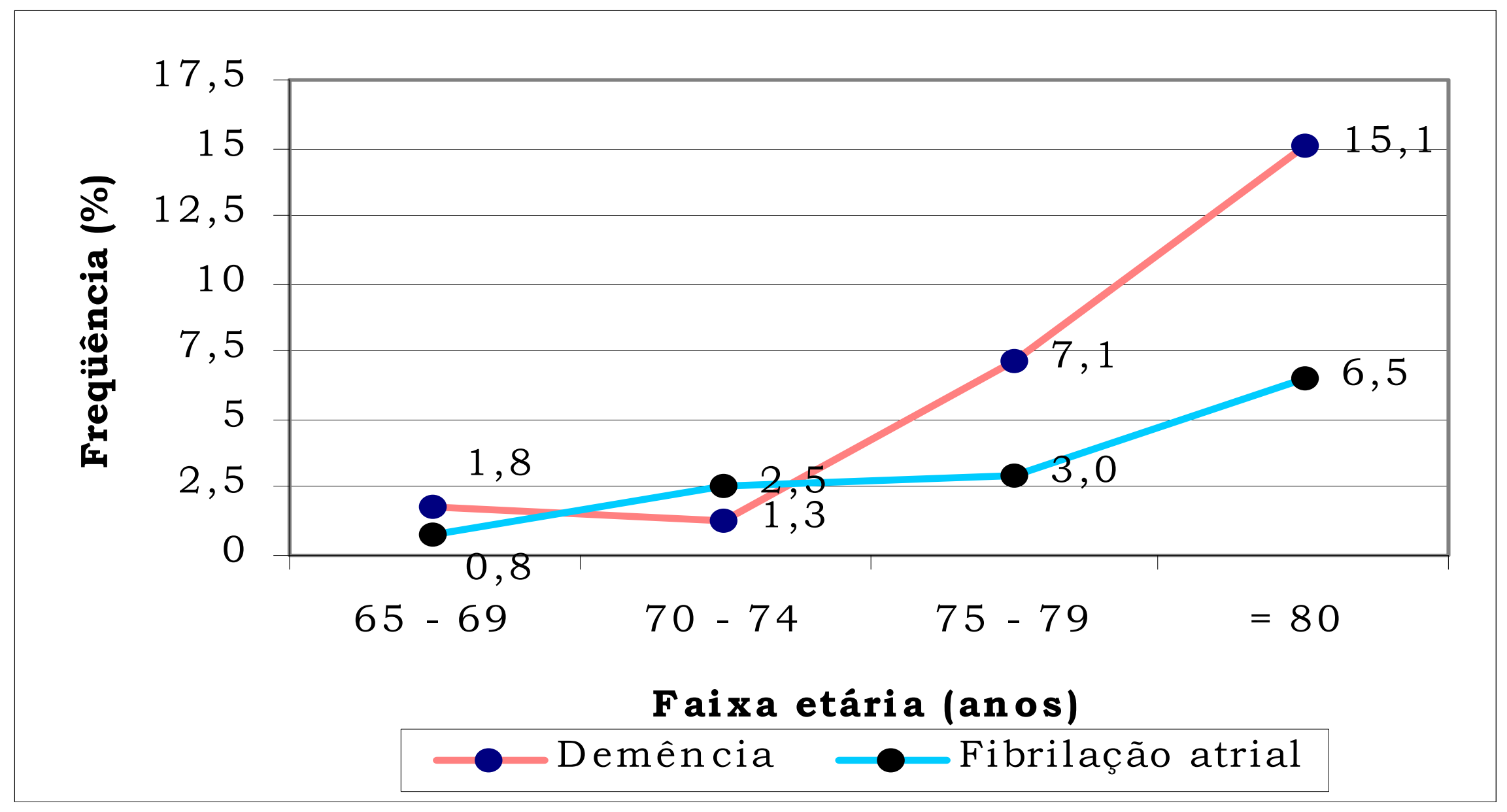

Figura 5 - Distribuição da freqüência de fibrilação atrial e de demência por faixa etária 
Tabela 12 - Associação entre demência e fibrilação atrial na amostra de participantes analisados de áreas cobertas pelo Programa Saúde da Família no distrito de saúde do Butantã, São Paulo (SP), em 2005

\begin{tabular}{lcc}
\hline Total de participantes & Participantes com demência (\%) & $X^{2}(P)$ \\
\hline Com fibrilação atrial & $4 / 36(11,1)$ & \\
Sem fibrilação atrial & $62 / 1488(4,2)$ & $4,09(0,043)$ \\
\hline Feminino & $3 / 17(17,7)$ & \\
\hline Com fibrilação atrial & $41 / 898(4,6)$ & $6,24(0,013)$ \\
Sem fibrilação atrial & $1 / 19(5,3)$ & \\
\hline Masculino & $21 / 590(3,6)$ & $0,15(0,695)$ \\
\hline Com fibrilação atrial & & \\
Sem fibrilação atrial & & \\
\hline
\end{tabular}

Estes dados foram submetidos à regressão logística, como apresentados na Tabela 13.

Tabela 13 - Razão de chances e intervalo de confiança de 95\% (IC 95\%) para fibrilação atrial e demência ajustado para sexo na amostra de participantes analisados de áreas cobertas pelo Programa Saúde da Família no distrito de saúde do Butantã, São Paulo (SP), em 2005

\begin{tabular}{lcc}
\hline Grupos & Razão de chances & IC 95\% \\
\hline Todos & 2,88 & $0,98-8,40$ \\
Feminino & 4,48 & $1,23-16,29$ \\
Masculino & 1,50 & $0,19-11,83$ \\
\hline
\end{tabular}

Foi também realizada a análise de demência com a presença de área inativa ao eletrocardiograma, sem que se encontrasse uma associação significativa, conforme os dados da Tabela 14 . 
Tabela 14 - Associação entre demência e presença de área inativa ao eletrocardiograma na amostra de participantes analisados de áreas cobertas pelo Programa Saúde da Família no distrito de saúde do Butantã, São Paulo (SP), em 2005

\begin{tabular}{lcc}
\hline Total de participantes & Participantes com demência (\%) & $\mathrm{X}^{2}(P)$ \\
\hline Com área inativa & $1 / 49(2,0)$ & $0,43(0,514)$ \\
Sem área inativa & $19 / 488(3,9)$ & \\
\hline Feminino & $1 / 42(2,4)$ & $0,47(0,491)$ \\
\hline Com área inativa & $35 / 752(4,7)$ & \\
Sem área inativa & & $0,98(0,323)$ \\
\hline Masculino & $2 / 91(2,2)$ & \\
\hline Com área inativa & $54 / 1240(4,4)$ & \\
Sem área inativa & & \\
\hline
\end{tabular}




\section{5 - Outras alterações eletrocardiográficas}

Outras alterações eletrocardiográficas de importância foram estudadas, além da fibrilação atrial crônica como: a determinação de área inativa com a presença de onda "Q" em derivações que indicam infarto do miocárdio prévio em parede ventricular, como a anterior, lateral superior e inferior e a presença do bloqueio de ramo esquerdo.

A Figura 6 mostra a presença de área inativa em pelo menos uma parede miocárdica analisada por sexo e faixa etária. Os dados mostram uma freqüência maior no sexo masculino e aumento progressivo com a idade.

A freqüência da área inativa foi de $97(6,3 \%)$ para a parede inferior, de $72(4,7 \%)$ para a parede lateral superior e de $43(2,8 \%)$ na parede anterior do ventrículo esquerdo.

A Figura 7 mostra a relação por parede ventricular da freqüência de área inativa por faixa etária. A alteração com menor aparecimento em todas as faixas etárias é aquela referente à lesão na parede anterior do ventrículo esquerdo. A prevalência ajustada por idade de área inativa ao eletrocardiograma foi de $12,4 \%$ com intervalo de confiança de 10,7 - 14,1. 


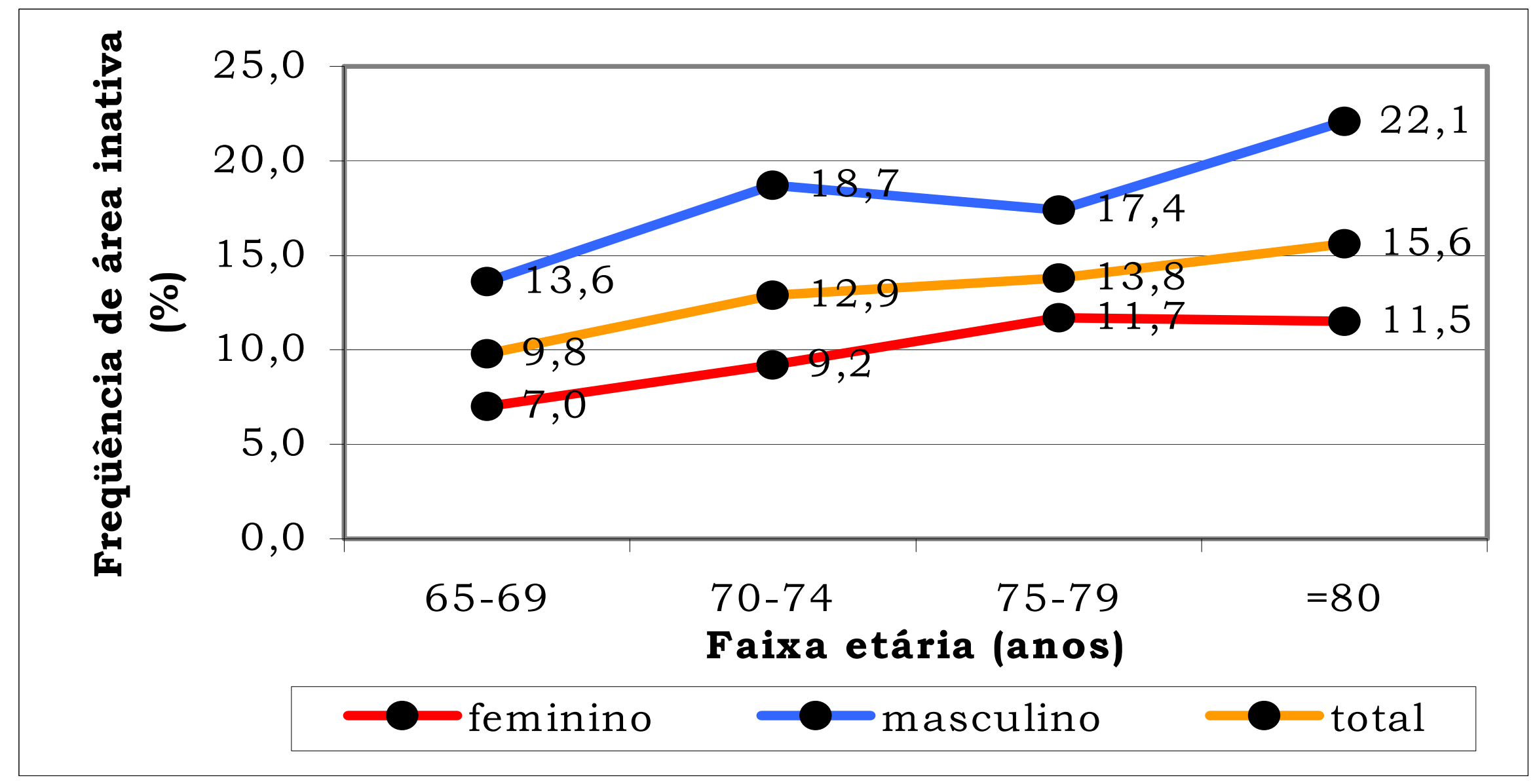

Figura 6- Distribuição da freqüência de área inativa ao eletrocardiograma por faixa etária e sexo 


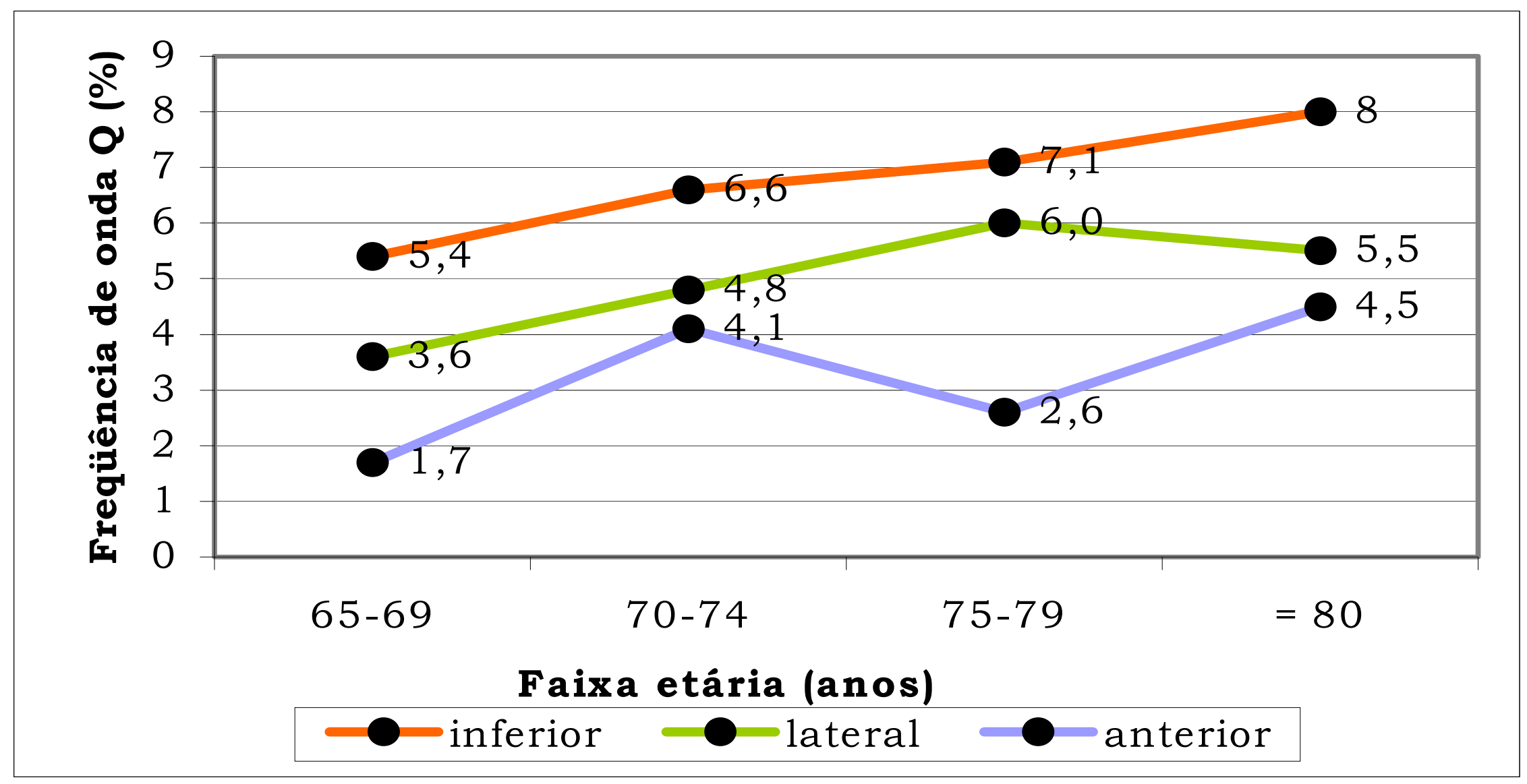

Figura 7 - Distribuição da freqüência de onda $Q$ por parede miocárdica acometida por faixa etária 
A Tabela 15 traz a relação entre pelo menos uma parede ventricular com indicação de infarto prévio com onda "Q". Houve nítida predominância entre os homens e nas faixas etárias mais elevadas e um predomínio nos negros, com uma menor freqüência nos orientais.

Em relação aos fatores de risco cardiovascular, a hipertensão arterial aparece como fator importante. Os outros fatores de risco não foram significativos na análise univariada (Tabela 16).

A associação entre área inativa e fibrilação atrial foi analisada (Tabela 17), sem que houvesse qualquer associação significativa. Porém, apesar da freqüência de área inativa anterior ser a menos importante, no estudo com a fibrilação atrial, ela se destaca.

O bloqueio completo de ramo esquerdo ao eletrocardiograma também foi estudado na amostra com variação pequena e não significativa com a idade no sexo masculino, conforme mostrado na Figura 8. Não houve qualquer outra associação com sexo ou qualquer outra característica socioeconômica, fatores de risco cardiovascular e morbidade, conforme apresentado nas Tabelas 18 e 19. A prevalência ajustada pela idade encontrada foi de $3,3 \%$ com intervalo de confiança de $95 \%$ de $2,4 \%-4,2 \%$. 
Tabela 15 - Associação entre as características sócio-econômicas e onda Q ao ECG na amostra de participantes analisados do Programa Saúde da Família no distrito do Butantã, São Paulo (SP), em 2005

\begin{tabular}{|c|c|c|}
\hline Característica & Área inativa ao ECG (\%) & $\mathrm{X}^{2}(P)$ \\
\hline \multicolumn{3}{|l|}{ Faixa etária (anos) } \\
\hline 65 a 69 & $65(9,8)$ & \\
\hline 70 a 74 & $51(12,9)$ & \\
\hline 75 a 79 & $37(13,8)$ & \\
\hline 80 ou mais & $31(15,6)$ & $6,47(0,091)$ \\
\hline \multicolumn{3}{|l|}{ Sexo } \\
\hline Feminino & $83(9,1)$ & \\
\hline Masculino & $101(16,6)$ & $19,44(0,000)$ \\
\hline \multicolumn{3}{|l|}{ Raça/etnia } \\
\hline Branca & $99(12,3)$ & \\
\hline Parda & $54(11,8)$ & \\
\hline Negra & $26(12,5)$ & \\
\hline Oriental & $2(4,6)$ & \\
\hline Outras & $3(33,3)$ & $11,01(0,051)$ \\
\hline \multicolumn{3}{|l|}{ Escolaridade (anos) } \\
\hline Analfabetos & $50(10,0)$ & \\
\hline $1-3$ anos & $11713,6)$ & \\
\hline Mais de 3 anos & $17(10,4)$ & $4,45(0,108)$ \\
\hline \multicolumn{3}{|l|}{ Renda mensal (SM) } \\
\hline Menos de 1 & $23(13,9)$ & \\
\hline $1-3$ & $108(11,6)$ & \\
\hline $4-5$ & $33(13,1)$ & \\
\hline $6-10$ & $14(10,1)$ & \\
\hline $11-15$ & $4(18,2)$ & \\
\hline $16-20$ & $2(15,4)$ & $2,47(0,780)$ \\
\hline \multicolumn{3}{|l|}{ Ocupação } \\
\hline Não trabalha & $78(17,7)$ & \\
\hline Trabalha & $34(9,6)$ & \\
\hline Dona-de-casa & $72(9,9)$ & $18,24(0,000)$ \\
\hline \multicolumn{3}{|l|}{ Estado civil } \\
\hline Solteiro & $9(15,3)$ & \\
\hline Casado & $102(14,2)$ & \\
\hline Viúvo & $48(9,0)$ & \\
\hline Divorciados/separados & $25(11,7)$ & $8,40(0,039)$ \\
\hline
\end{tabular}


Tabela 16 - Associação entre os fatores de risco cardiovascular e áreas inativas ao eletrocardiograma de repouso na amostra de participantes analisados de áreas cobertas pelo Programa Saúde da Família no distrito de saúde do Butantã, São Paulo (SP), em 2005

\begin{tabular}{lcc}
\hline Fator de risco & $\mathrm{X}^{2}(P)$ \\
\hline Hipertensão & $160(13,5)$ & \\
\hline Sim & $20(6,4)$ & $11,92(0,001)$ \\
Não & & \\
\hline Diabetes & $46(13,6)$ & $1,09(0,297)$ \\
\hline Sim & $130(11,5)$ & \\
Não & $89(11,9)$ & $0,05(0,822)$ \\
\hline Dislipidemia & $95(12,3)$ & \\
\hline Sim & & $1,98(0,372)$ \\
Não & $32(12,0)$ & \\
\hline IMC $\left(\mathrm{kg} / \mathrm{m}^{2}\right)$ & $55(10,5)$ & \\
\hline$<25,0$ & $89(13,1)$ & \\
$25,0-29,9$ & & \\
$\geq 30,0$ & & \\
\hline
\end{tabular}


Tabela 17 - Fibrilação atrial e áreas inativas no eletrocardiograma por região acometida na amostra de participantes analisados de áreas cobertas pelo Programa Saúde da Família no distrito de saúde do Butantã, São Paulo (SP), em 2005

\begin{tabular}{lcc}
\hline Localização & Fibrilação atrial (\%) & $\mathrm{X}^{2}(P)$ \\
\hline Parede inferior & 3,1 & \\
\hline Sim & 2,3 & $0,25(0,619)$ \\
Não & & \\
\hline Parede lateral & 1,4 & $0,27(0,601)$ \\
\hline Sim & 2,4 & \\
Não & & $4,12(0,042)$ \\
\hline Parede anterior & 7,0 & \\
\hline Sim & 2,2 & $1,92(0,166)$ \\
Não & & \\
\hline Total & 3,8 & \\
\hline Sim & 2,2 & \\
Não & & \\
\hline
\end{tabular}




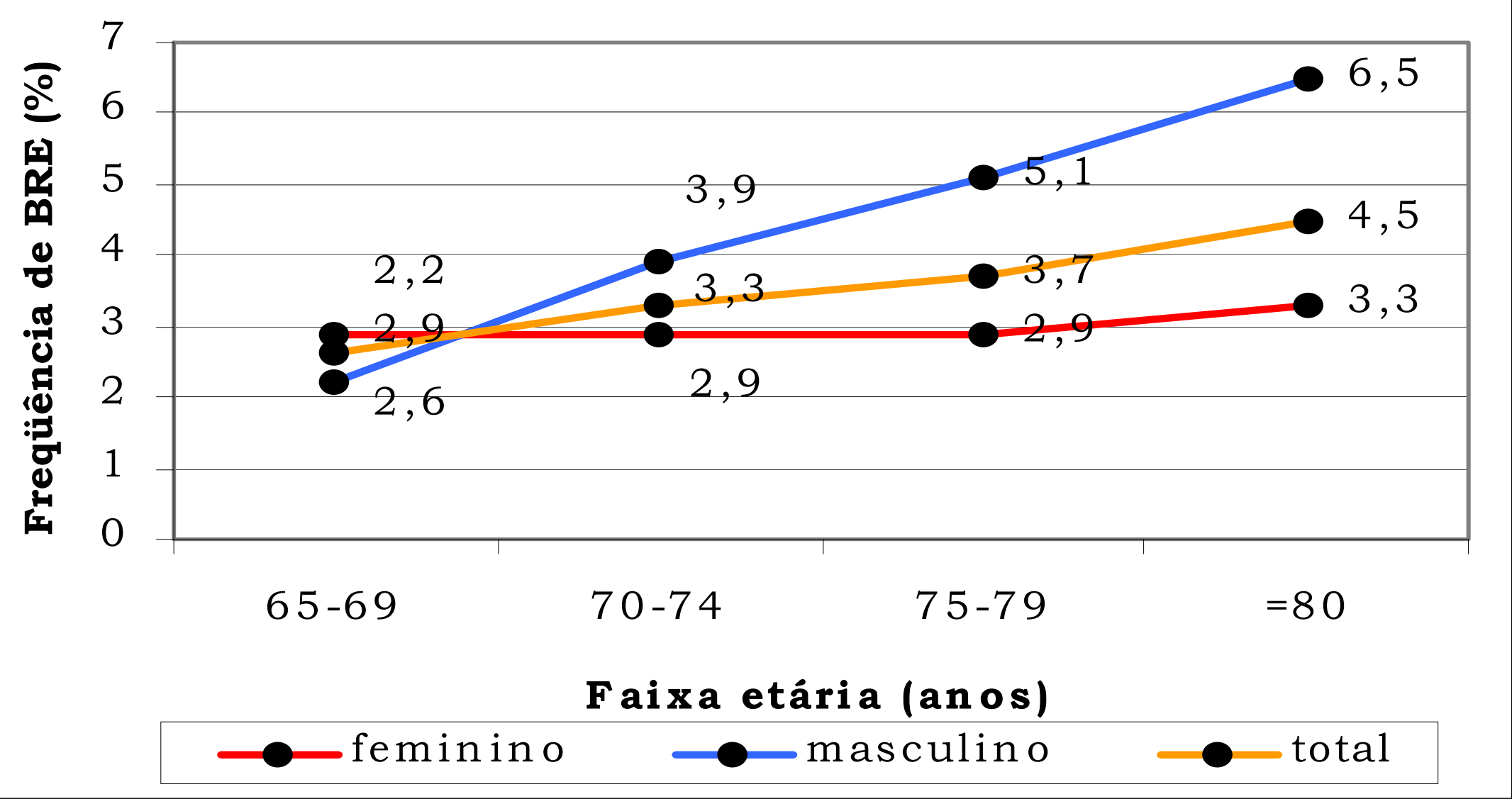

Figura 8 - Distribuição da freqüência de bloqueio de ramo esquerdo por faixa etária e sexo 
Tabela 18 - Associação de fatores de risco sócio-demográficos e bloqueio de ramo esquerdo na amostra de participantes do Programa Saúde da Família no distrito do Butantã, São Paulo (SP), em 2005

\begin{tabular}{|c|c|c|}
\hline Característica & BRE (\%) & $\mathrm{X}^{2}(P)$ \\
\hline \multicolumn{3}{|l|}{ Faixa etária (anos) } \\
\hline 65 a 69 & $17(2,6)$ & \\
\hline 70 a 74 & $13(3,3)$ & \\
\hline 75 a 79 & $10(3,7)$ & \\
\hline 80 ou mais & $9(4,5)$ & $2,21(0,530)$ \\
\hline \multicolumn{3}{|l|}{ Sexo } \\
\hline Feminino & $27(3,0)$ & \\
\hline Masculino & $22(3,6)$ & $0,51(0,473)$ \\
\hline \multicolumn{3}{|l|}{ Raça/etnia } \\
\hline Branca & $32(4,0)$ & \\
\hline Parda & $10(2,2)$ & \\
\hline Negra & $6(2,9)$ & \\
\hline Oriental & $1(2,3)$ & \\
\hline Outras & $0(0,0)$ & $3,59(0,609)$ \\
\hline \multicolumn{3}{|l|}{ Escolaridade (anos) } \\
\hline Analfabetos & $19(3,8)$ & \\
\hline $1-3$ anos & $27(3,1)$ & \\
\hline 4 anos ou mais & $3(1,8)$ & $1,56(0,458)$ \\
\hline \multicolumn{3}{|l|}{ Renda mensal (SM) } \\
\hline Menos de 1 & $6(3,6)$ & \\
\hline $1-3$ & $31(3,3)$ & \\
\hline $4-5$ & $9(3,6)$ & \\
\hline $6-10$ & $2(1,4)$ & \\
\hline $11-15$ & $0(0,0)$ & \\
\hline $16-20$ & $1(7,7)$ & $3,21(0,667)$ \\
\hline \multicolumn{3}{|l|}{ Ocupação } \\
\hline Não trabalha & $19(4,3)$ & \\
\hline Trabalha & $6(1,7)$ & \\
\hline Dona-de-casa & $24(3,3)$ & $4,34(0,114)$ \\
\hline \multicolumn{3}{|l|}{ Estado civil } \\
\hline Solteiro & $2(3,4)$ & \\
\hline Casado & $23(3,2)$ & \\
\hline Viúvo & $16(3,0)$ & \\
\hline Divorciados/separados & $8(3,7)$ & $0,27(0,965)$ \\
\hline
\end{tabular}


Tabela 19 - Associação entre os fatores de risco cardiovascular e presença de bloqueio de ramo esquerdo na amostra de participantes analisados de áreas cobertas pelo Programa Saúde da Família no distrito de saúde do Butantã, São Paulo (SP), em 2005

\begin{tabular}{lcc}
\hline Fator de risco & BRE (\%) & $\mathrm{X}^{2}(P)$ \\
\hline Hipertensão & $41(3,5)$ & $1,21(0,272)$ \\
\hline Sim & $7(2,2)$ & \\
Não & & $0,11(0,742)$ \\
\hline Diabetes & $12(3,5)$ & \\
\hline Sim & $36(3,2)$ & $0,07(0,790)$ \\
\hline Dislipidemia & & \\
\hline Sim & $25(3,3)$ & \\
Não & $24(3,1)$ & $0,60(0,740)$ \\
\hline IMC $\left(\mathrm{kg} / \mathrm{m}^{2}\right)$ & & \\
\hline$<25,0$ & $21(3,1)$ & \\
$25,0-29,9$ & $19(3,6)$ & \\
$\geq 30,0$ & $7(2,6)$ & \\
\hline
\end{tabular}




\section{5 - Discussão}




\section{1 - Sobre o estudo}

A cidade de São Paulo é muito complexa do ponto de vista social. Apesar de possuir um sistema de saúde equipado com a mais alta tecnologia, poucos são os que têm acesso a ela. Os idosos apresentam ainda maior dificuldade de acesso à assistência médica, pois dependem de outros em virtude de suas limitações mentais ou mesmo físicas, como andar e enxergar. A fragilidade marca estes indivíduos: envelhecimento biológico acrescido de condições crônicas, abuso (tabagismo, alcoolismo) e desuso (sedentarismo) (Chaimowics, 1997). Esta situação predispõe a doenças e incapacidades. Se não conseguirmos postergar o aparecimento destas enfermidades, veremos que os anos de vida ganhos serão vividos apenas para aumentar a proporção de incapacidade e de doenças.

Este é o primeiro estudo brasileiro de base populacional com o objetivo de estudar alterações eletrocardiográficas entre idosos residentes na periferia de São Paulo quanto à presença de fibrilação atrial, provável doença coronariana e bloqueio de ramo esquerdo. Também é o primeiro que tem o intuito de correlacionar fibrilação atrial com demência. Destaque-se o fato que o objeto de estudo foi uma população pobre e idosa. 
As internações hospitalares da população nesta faixa etária estão aumentando e o custo delas também. Apesar dos idosos representarem uma menor parcela da população, é ela que consome a maior parte dos recursos da saúde. Em 2001, os idosos correspondiam a $14,3 \%$ da população adulta e contribuíram com $33,5 \%$ das internações e $37,7 \%$ dos recursos pagos pelas mesmas (Peixoto et al., 2004).

A determinação destas taxas de prevalência é importante, principalmente em relação às políticas públicas, pela possibilidade de programar medidas preventivas primárias e secundárias que diminuam a incidência de doenças que levam a internações, seqüelas, disautonomia e mortalidade. Essas medidas podem ter impacto além da população geriátrica, com beneficios da população como um todo, porque pode permitir uma melhor alocação dos recursos disponiveis.

Esta tese, por exemplo, possibilitou a detecção de uma deficiência na atenção ambulatorial dispensada à população em relação aos casos que necessitavam de anticoagulação. Estes casos, muitas vezes, eram atendidos no pronto-socorro pela grande demanda ambulatorial em relação às vagas disponíveis, sobrecarregando o atendimento de emergências. A criação de um ambulatório de anticoagulação com controle telefônico da varfarina, 
conseguiu oferecer o melhor tratamento a um número maior de pessoas. Essa monitorização inclusive, permitiu o melhor controle dos valores do INR e o controle dos indivíduos menos aderentes, que faltavam as consultas e, como resultado inicial, já conseguimos observar uma tendência de queda do efeito colateral mais temido: o sangramento.

\section{2 - Eletrocardiograma}

O eletrocardiograma é uma ferramenta acessível, de fácil manuseio, portátil e prática, que tem sido utilizada tanto para "screening" como para detectar doença cardíaca e que pode auxiliar muito na avaliação de doença cardiovascular no contexto populacional. A identificação precoce de arritmias, tais como a fibrilação e o flutter atrial, tornam possivel reduzir incidência, letalidade e seqüelas da doença cerebrovascular (Fuster et al., 2006), assim como encontrar sinais de doença coronariana silenciosa ou de bloqueio de ramo esquerdo, marcadores de hipertensão avançada ou doença coronariana ou cardíaca, pode auxiliar a diminuir a incidência de insuficiência cardíaca (Schineider et al., 1981), de arritmias e, consequentemente também de doenças cerebrovasculares. 


\section{3 - População}

Na população estudada, pouco mais de $30 \%$ tinham mais de 75 anos. Predominou o sexo feminino (60\%). O grau de escolaridade era realmente baixo, quase $90 \%$ com menos de três anos de estudo e alta taxa de analfabetos. Esta realmente foi uma amostra de população de baixa renda: em mais de $70 \%$ a renda foi inferior a três salários, com uma população ainda bastante ativa, 23,3\% trabalhavam e contribuiam com a renda familiar de forma participativa e não apenas com beneficios previdenciários. Quinhentos e trinta e três participantes (35\% da população) eram viúvos, sendo que $84,8 \%$ eram do sexo feminino e $57,5 \%$ tinham menos de 75 anos, o que reflete a mortalidade precoce do sexo masculino. Os que não tinham companheiro (solteiros, viúvos e separados/divorciados) e com 80 anos ou mais corresponderam a $9,1 \%$ da população, ou a $69,3 \%$ da população desta faixa etária. Apesar de se esperar que, em função da idade avançada, a maioria deles necessitasse de cuidado de outras pessoas, menos de um terço deles era casada e podia contar com o suporte ao menos do cônjuge.

\section{4 - Hipertensão arterial}

Esta era uma população com alta taxa de hipertensão arterial $(77,8 \%)$, uma freqüência bem maior quando comparada com outros 
estudos populacionais prévios. Freitas e colaboradores (2001) estudaram a população adulta acima de 18 anos de Catanduva e encontraram uma taxa de $31,5 \%$ (prevalência de 44,0\% nos homens e $52,1 \%$ nas mulheres) acima de 70 anos; e que demonstraram niveis pressóricos mais elevados na população de menor renda e escolaridade e também entre viúvos e divorciados. Neste estudo, não se encontrou diferença com a renda e o estado civil, apenas com a baixa escolaridade $(P=0,027)$. A prevalência de Passo Fundo (Trindade et al., 1998) em população adulta geral foi de 21,9\%, mas este estudo utilizou como critério o padrão de hipertensão da OMS (niveis pressóricos acima de 160 por $90 \mathrm{mmHg}$ ). Na cidade de Pelotas, a prevalência foi de 46,9\% para a população de 60-69 anos (Piccini et al., 1994). Em Campinas (Zaitune et al., 2006), um estudo em população acima de 60 anos, o dado encontrado foi de 46,4\% no sexo masculino e 55,9\% no sexo feminino, tendo uma idade média de 69,8 , um pouco menor que a deste estudo, talvez porque a população também fosse um pouco mais nova. A análise de Tubarão (Pereira et al., 2007) encontrou a prevalência de 67,8 e $66,2 \%$ entre idosos masculinos e femininos, respectivamente, de 60 a 65 anos, mais semelhante à encontrada em nossa casuística, porém limitada a esta faixa etária.

Desprezando-se as medidas de pressão arterial e utilizando apenas os dados apenas de uso de anti-hipertensivos, ou seja, estar 
em tratamento para hipertensão, encontrou-se uma freqüência de $60 \%$ desta doença. Isso talvez pudesse diminuir o erro da superestimativa da medida que foi realizada em apenas uma visita, entretanto esta conduta subestimaria os casos que, por falta de acesso, não tiveram o diagnóstico realizado e o adequado tratamento instituído. Talvez o valor obtido seja maior por se tratar de uma população mais idosa e urbana (Fuentes et al., 2000).

\section{5 - Diabetes mellitus}

Em relação ao diabetes mellitus, encontramos uma freqüência também alta, de 22,4\%, mesmo que, para o diagnóstico, tenha sido utilizados apenas a glicemia de jejum e o fato do indivíduo utilizar medicações, quando comparada com dados da cidade do Rio de Janeiro com uma prevalência de $7,1 \%$ na população de 30 a 69 anos em 1994 (Oliveira et al., 1996). Estudos mais recentes aproximam-se do valor observado em nossa casuística, como o estudo multicêntrico (Goldenberg et al., 2003) realizado em nove capitais brasileiras, que encontrou diabetes diagnosticado em $10,1 \%$ e fez diagnóstico em $7,7 \%$ dos indivíduos, numa população de 50 a 69 anos, com glicemia capilar de jejum e com glicemia 2 horas após sobrecarga de $75 \mathrm{~g}$ glicose. Em Ribeirão Preto, Torquato e colaboradores (2003) encontrou a prevalência de $21,7 \%$ de diagnóstico de diabetes na população de 60-69 anos e 11,3\% com teste de sobrecarga positivo. A 
prevalência encontrada dessa doença, em população acima de 60 anos em seis países da América Latina foi de 16,9\% (Barcelo et al., 2006); já entre os americanos acima de 60 anos, a mesma foi de 20,9\% segundo o National Diabetes Statistics (2005), mesmo tendo uma população muito mais obesa que a estudada.

Apesar da prevalência ter sido alta neste trabalho, ela pode ainda estar subestimada se considerarmos que não foram feitos diagnósticos em indivíduos com valores intermediários de glicemia de jejum, pois não foi realizado uma glicemia pós-prandial ou um teste de sobrecarga de glicose.

Existe uma previsão de que esta freqüência de diabetes mellitus na população aumente cada vez em função do envelhecimento, da urbanização, da inatividade e do aumento da obesidade (Wild et al., 2004). Mesmo se a incidência de obesidade se mantivesse estável até 2030, o que é improvável, o número de casos de diabetes mellitus aumentará em duas vezes (Lotufo, 2000) por causa dos outros fatores mencionados.

\section{6 - Dislipidemia}

A dislipidemia é um termo genérico que pode englobar várias definições. São estabelecidos níveis adequados de acordo com as 
doenças associadas e com outros fatores de risco; além disso, os dados são muito variáveis de região para região devido aos hábitos culturais e dietéticos. Em 1995, em Salvador, foi publicada uma casuística que avaliava individuos acima de 20 anos e valores de LDL maior ou igual a 160 e a prevalência encontrada de dislipidemia segundo este critério foi de $26,1 \%$ dos homens e $33,1 \%$ nas mulheres (Lessa et al., 1997), valor abaixo dos desse estudo, 49,8\% para o sexo feminino e $48,1 \%$ para o sexo masculino. Por outro lado, em um estudo populacional, acima de 18 anos, em Campos dos Goytacazes, encontrou-se uma prevalência de $31 \%$ acima de 70 anos (Souza et al., 2003a) utilizando-se para avaliação o III Guideline Brasileiro de Dislipidemia que engloba outros dados além do LDL.

No nosso estudo observou-se um valor alto mesmo considerando-se apenas o valor do LDL e não levando em consideração o valor ideal quando há outros fatores de risco envolvidos, como nos pacientes diabéticos nos quais o valor de LDL desejado é menor.

\section{7 - Obesidade}

A prevalência de obesidade vem aumentando progressivamente, ganhando proporções epidêmicas. 
Nos Estados Unidos, a prevalência de sobrepeso é de 30\% e a de obesos é de 32\% (Grundy et al., 2008). Segundo Arteburn e colaboradores (2004), é de 32\% em indivíduos acima de 60 anos, com a previsão de chegar a 37,4\% em 2010.

No Brasil, em 1974, a prevalência era de 2,4\% e 7,0\% (homens e mulheres respectivamente) e, em 1996, chegou a 6,9\% e 12,5\%, devido à mudança de hábitos alimentares e ao sedentarismo (Lotufo, 2000).

Em relação à população geral, o índice de massa corpórea da população em estudo foi bem diferente dos dados do IBGE de 20022003, que avaliou dados da população com mais de 20 anos. Nosso estudo encontrou um valor pouco maior de obesidade, de $14,1 \%$ no sexo feminino (valor do IBGE 13,1\%) e menor no sexo masculino 3,4\% (valor do IBGE 8,9\%). Em relação ao sobrepeso, a prevalência foi bem menor, de 19,6\% para o sexo feminino e de $14,8 \%$ para o sexo masculino (IBGE: 40,0\% e 41,1\% respectivamente), mesmo o estudo englobando apenas pessoas com 65 anos ou mais. Souza e colaboradores (2003b), em Campinas, encontrou-se uma prevalência de obesidade na população de $17,8 \%$ e $32,8 \%$ de sobrepeso e, na população acima de 70 anos, o valor foi de $13,5 \%$, predominando no sexo feminino. 
A obesidade representa um grande problema por ser o maior fator de risco das doenças crônicas não infecciosas (diabetes, doenças cardiovasculares - doenças cardíacas, hipertensão arterial, acidente vascular cerebral e câncer) (World Health Organization, 2006). Talvez a obesidade crescente seja uma das causas do declínio lento da mortalidade por doenças cardiovasculares no Brasil (Lotufo, 2000), processo que vem lentamente sendo observado no mundo.

\section{8 - Demência e fibrilação atrial}

Os resultados obtidos mostraram que, tanto a prevalência de fibrilação atrial como a de demência, na população carente do Distrito do Butantã, aumentaram com a idade, porém a demência numa intensidade maior do que a fibrilação atrial. $\mathrm{O}$ valor obtido para fibrilação atrial de 2,7\% foi bem menor do que o valor utilizado para o cálculo da amostra, porém para demência o valor obtido de $4,9 \%$ foi maior, talvez devido à metodologia ampla empregada que permitiu mais diagnósticos, tentando minimizar o viés de escolaridade.

A anticoagulação com varfarina reduz o risco de eventos embólicos em 65 a 80\% (Atrial Fibrillation Investigations, 1994) e o uso de aspirina reduz o risco em 44\%. Ambas as medicações diminuem a incidência de acidente vascular cerebral, atuando na 
prevenção primária e secundária, além de reduzir a mortalidade em 33\%. A ticlopidina, outro antiagregante plaquetário, parece ter efeito pouco superior a aspirina, porém com mais efeitos colaterais, principalmente o preço em nosso meio (Hankey et al., 2002). A indicação de um ou de outro tratamento se dá pelos fatores de risco. Pacientes com um destes itens: hipertensão, insuficiência cardíaca, diabetes, mais de 75 anos, com acidente vascular cerebral prévio, doença reumática valvar ou disfunção moderada ou severa de ventrículo direito devem ser anticoagulados (Gage et al., 2001). Se o paciente tiver idade entre 65-75 anos, sem nenhum dos riscos acima mencionados, tanto pode ser anticoagulado como receber aspirina. $\mathrm{E}$ paciente com menos de 65 anos, sem fatores de risco poderá receber apenas aspirina. A aspirina por sua vez, apesar de não exigir um controle clínico e laboratorial rigoroso, apresenta efeitos colaterais que não são despreziveis (Rash et al., 2007), principalmente no trato gastrointestinal. O problema, nesta fase, é do alto custo e efeitos colaterais dos medicamentos, pois a freqüência cardíaca também deve ser controlada.

Encontrou-se também que apenas $50 \%$ dos indivíduos da população da pesquisa que tinha fibrilação ou flutter atrial recebiam algum tratamento preventivo para acidente cerebrovascular, sendo que menos de um quarto recebia varfarina, e que esse tratamento predominou nos indivíduos mais novos. 
Mesmo sabendo que indivíduos portadores de fibrilação atrial permanente ou persistente devem ser tratados, todavia, sabe-se que 90\% das arritmias paroxísticas apresentam episódios recorrentes (Israel et al., 2004), dos quais mais de 90\% são assintomáticas (Page et al., 1994) e 17\% podem durar mais que 48 horas (Desmond et al., 2002). Estes casos também apresentam risco mas não temos como quantifica-los.

Vários estudos têm mostrado correlação de fatores de risco cardiovascular com demência e também a correlação deles com a doença de Alzheimer, todavia não há dados conclusivos (Bhargava et al., 2006; Silvestrini et al., 2006; Regan et al., 2006). A confirmação de uma relação positiva seria importante na prevenção primária desta doença. Se pudermos atuar "comprimindo a morbidade" (Chaimowicz, 1997), ou seja, adiando o tempo de surgimento das doenças, diminuindo o intervalo de tempo entre o início da doença ou incapacidade e a morte, através de medidas de prevenção da obesidade, do estresse, do sedentarismo, do tabagismo, controlando adequadamente a hipertensão arterial, o diabetes mellitus e a dislipidemia diminuindo o risco de problemas cardiovasculares, poderá se alcançar este objetivo. Porém, este estudo não encontrou correlação de demência com os fatores de risco cardiovascular estudados. Encontrou-se uma prevalência de demência maior que de 
fibrilação atrial e uma relação estatisticamente significativa entre as duas doenças estudadas, no entanto apenas no sexo feminino. Na linha de base do Rotterdam Study, foi possivel verificar a associação positiva de fibrilação atrial com a demência como déficit cognitivo com razões de chance de 2,3 e 1,7, respectivamente. Essa associação foi mais pronunciada em mulheres e em idosos relativamente mais jovens, principalmente com menos de 75 anos (Ott et al., 1997). Uma coorte de base populacional, a Olmsted County, Minnesota (Estados Unidos) seguiu indivíduos com fibrilação atrial excluindo aqueles com acidente vascular cerebral. Nessa coorte, foi possivel identificar que o diagnóstico de demência após fibrilação atrial foi associado a uma maior letalidade (Miyasaka et al., 2007). Este estudo mostrou aumento de casos demenciais após o diagnóstico de fibrilação atrial, sendo que a taxa cumulativa de Kaplan-Meyer foi $2,7 \%$ no final do primeiro ano e 10,5\% ao final do quinto ano de observação.

Tanto a fibrilação atrial quanto a demência podem causar um viés de sobrevivência, e esta associação pode estar subestimada neste estudo. A fibrilação atrial causa não apenas tromboembolismo, como também pode levar a uma hipoperfusão por diminuição do débito cardíaco. Este último poderia ser um outro mecanismo que relacione a fibrilação atrial com demência não apenas vascular, mas também à demência por doença de Alzheimer. Nosso estudo não pode ser conclusivo, nesse sentido, talvez porque estudamos dois eventos de 
baixa freqüência, apesar do alto impacto social e econômico na população.

Purandare e colaboradores (2006) encontraram associação entre êmbolos cerebrais espontâneos e demência através do doppler transcraniano. Este trabalho trouxe também a discussão entre doença de Alzheimer e demência vascular, talvez não como patologias distintas, mas como uma mistura destas doenças, uma superposição dessas doenças. Se comprovada a interação vascular e neurodegenerativa como causa de demência após o acidente vascular cerebral, as implicações terapêuticas serão enormes. Recentes estudos têm mostrado o valor das estatinas (Li et al., 2004; Zamrini et al., 2004) e inibidores da enzima de conversão da angiotensina em adição às drogas antitrombóticas na prevenção de Alzheimer e acidente vascular cerebral. Talvez seja benéfica a utilização de inibidores anticolinesterásicos para diminuir a progressão do processo neurodegenerativo (Desmond et al., 2002). A prevenção primária e secundária do acidente vascular cerebral deverá diminuir o risco de todas as demências.

\section{9 - Área inativa ao eletrocardiograma}


Alterações isquêmicas no eletrocardiograma estão associadas a duas vezes o risco de se morrer por doença coronariana. No Framingham Heart Study, a prevalência de alterações isquêmicas é de $2,1 \%$ em homens e 1,7\% em mulheres, na faixa etária de 30 a 62 anos (Shurtleff et al., 1974). A relação entre os sexos mostra uma prevalência maior no sexo masculino do que no feminino $(2,0 \%$ e 0,6\%, respectivamente) no estudo ARIC (Vitelli et al., 1998).

Em relação às áreas isquêmicas, encontramos maior prevalência em homens e que ela aumenta com os anos nas diferentes faixas etárias, conforme observamos na literatura e no diaa-dia de atendimento. A alteração mais freqüentemente encontrada foi na parede inferior e a menos freqüente foi na parede anterior. Em relação aos fatores de risco cardiovascular, encontramos apenas a correlação com a inatividade laboral e com o fato de que solteiros e casados serem mais acometidos, além da diferença dos sexos já mencionada. Houve correlação da hipertensão com a presença de área isquêmica, sem relação com diabetes, dislipidemia ou obesidade. Não foi observada associação significativa na análise das áreas isquêmicas e sua correlação com a fibrilação atrial.

\subsection{0 - Bloqueio de ramo esquerdo}


Observando os dados de bloqueio de ramo esquerdo encontramos que esta alteração não teve qualquer variação com quaisquer das variáveis, exceto idade para o sexo masculino. Porém, a importância prognóstica dessa alteração eletrocardiográfica foi estudada no Framingham Heart Study, que seguiu 55 participantes (idade média de 62 anos) com esta alteração (Schneider et al., 1979), com $62 \%$ de hipertensos e metade com cardiomegalia na radiografia de tórax. Também demonstrou que o bloqueio está associado com hipertensão, doença arterial coronariana ou cardiomiopatia ou com maior risco de desenvolvê-las. Neste acompanhamento de 18 anos, $89 \%$ dos pacientes desenvolveram algum tipo de doença coronariana enquanto apenas $50 \%$ da população sem o bloqueio de ramo esquerdo.

O bloqueio de ramo esquerdo, mesmo na ausência de cardiopatia e de fatores sabidamente conhecidos como de risco para doenças cardiovasculares, aumenta o risco de apresentá-las e apresenta aumento da mortalidade (Miller et al., 2005). Parece ser um marcador de doença cardíaca e da necessidade de transplante (Grigioni et al., 2003). Eriksson e colaboradores (1998) encontraram que a prevalência de bloqueio de ramo esquerdo aumenta de $1 \%$ aos 50 anos para $17 \%$ aos 80 anos, resultando numa incidência acumulada de $18 \%$. Outro estudo que avaliou indivíduos de 33 a 71 anos encontrou uma prevalência de $0,43 \%$ para homens e $0,28 \%$ 
para mulheres (Hardarson et al., 1987). A prevalência encontrada neste estudo foi de 3,3. Em pacientes com insuficiência cardíaca foi encontrada uma prevalência bem maior de 25,2\% (Baldasseroni et al., 2002). Eriksson e colaboradores (2005) encontraram também um aumento de bloqueio cardíaco de alto grau, aumento do risco da necessidade de implantação marca-passo e de estenose aórtica na população masculina de Gotenborg.

\subsection{1 - Limitações do estudo}

Este é um estudo transversal, que permitiu observar várias características da população observada, uma população economicamente desfavorecida com uma prevalência alta dos vários fatores de risco cardiovascular. Talvez a freqüência baixa da fibrilação atrial crônica encontrada se deva ao viés de sobrevivência, os pacientes mais graves não sobrevivem e como a fibrilação atrial está, pelo menos, associada com insuficiência cardíaca, doença pulmonar obstrutiva crônica e acidente vascular cerebral, pode-se entender este achado. E esse viés de sobrevivência merece destaque, afinal as duas variáveis, demência e fibrilação atrial aumentam a mortalidade, o que pode ter dificultado o encontro de uma associação mais forte entre elas. 
Como outra limitação deste estudo podemos citar: o eletrocardiograma de repouso, método utilizado, que não é capaz de detectar a arritmia controlada com medicação ou a fibrilação atrial paroxística. No Cardiovascular Heart Study observou-se que o exame de eletrocardiograma de repouso conseguiu detectar apenas $74 \%$ de fibrilação atrial nos pacientes que apresentavam esta arritmia no eletrocardiograma de 24 horas (Manolio et al, 1994). Este exame também é incapaz de diagnosticar todas as isquemias, pois muitas evoluem com morte súbita e, também, o próprio método tem limitação em detectar acometimento em todas as paredes do miocárdio (infartos não "Q"). Ainda há os indivíduos que tiveram uma isquemia miocárdica e que receberam tratamento com tromboliticos ou angiopatia de resgate, pois nesses pacientes tratados, as alterações esperadas de isquemia podem não ser mais detectáveis pelo método, o tratamento instituído pode revertê-las totalmente. 
6 - Conclusões 
Em uma população idosa, moradora em região economicamente desfavorecida da cidade de São Paulo foi possivel identificar prevalência elevada de fatores de risco cardiovascular como hipertensão, diabetes mellitus, dislipidemia e obesidade. Foi também observada uma prevalência elevada de cardiopatia coronariana, baseada nas alterações eletrocardiográficas sugestivas de isquemia miocárdica, principalmente em homens hipertensos.

A prevalência de fibrilação atrial encontrada nesta população foi menor que a esperada. Esse achado provavelmente se deva a um um viés de sobrevivência da população estudada, onde a proporção de morte prematura é elevada. A prevalência de demência, no entanto, foi maior que a esperada, talvez por se utilizar um instrumento com maior precisão do que os aplicados em outros inquéritos.

A correlação de fibrilação atrial crônica e demência nessa população de idosos, foi positiva no sexo feminino. Como estes dados foram obtidos em um estudo transversal, eles deverão ser comprovados em estudo longitudinal, no entanto, já indicam a importância da identificação de fatores de risco e de fibrilação atrial em população idosa. 
$\underline{\text { Referências Bibliográficas* }}$ 
American Psychiatric Association. Diagnostic and statistic manual of mental disorders: DSM-IV. 4th ed. Washington: American Psychiatric Association; 1994.

Anstey KJ, von Sanden C, Salim A, O'Kearney R. Smoking as a risk factor for dementia and cognitive decline: a meta-analysis of prospective studies. Am J Epidemiol. 2007; 166(4): 367-78.

Arterburn D, Crane P, Sullivan S. The coming epidemic of obesity in elderly americans. J Am Geriatrics Society. 2004; 52(11):1907-12.

Atrial Fibrillation Investigators. Risk factors for stroke and efficacy of antithrombotic therapy in atrial fibrillation. Analysis of pooled data from five randomized controlled trials. Arch Intern Med.1994; 154(13): 1449-57.

Baldasseroni S, Opasich C, Gorini M, Lucci D, Marchionni N, Marini $\mathrm{M}$, et al. Left bundle-branch block is associated with increased 1-year sudden and total mortality rate in 5517 outpatients with congestive heart failure: A report from the Italian network on congestive heart failure. Am Heart J. 2002; 143(3): 398-405.

Barba R, Martínez-Espinosa S, Rodríguez-García E, Pondal M, Vivancos J, Del Ser T. Poststroke dementia: clinical features and risk factors. Stroke. 2000; 31(7):1494- 501.

Barcelo A, Pelaez M, Rodriguez-Wong L, Pastor-Valero M. The prevalence of diabetes among the Elderly in six countries: the Health, Wellbeing and Ageing (SABE) Project. $J$ Ageing Health. 2006; 18(2):224-39.

Benjamin EJ, Wolf PA, D'Agostino RB, Silbershatz H, Kannel WB, Levy D. Impact of atrial fibrillation on the risk of death: the Framingham Heart Study. Circulation. 1998; 98(10):946-52.

Bhargava D, Weiner MF, Hynan LS, Diaz-Arratia R, Lipton AM. Vascular disease and risk factors, rate of progression, and survival in Alzheimer's disease. J Geriatr Psychiatry Neurol. 2006; 19(2):78-82.

Biessels GJ, Staekenborg S, Brunner E, Brayne C. Risk of dementia in diabetes mellitus: a systematic review. Lancet Neurol. 2006; $5(2): 64-74$.

Brasil - Ministério da Saúde. DATASUS. Indicadores Demográficos [Internet]. Brasília: DATASUS; 2006 \{cited 2008 May 28]. Available from: http://tabnet.datasus.gov.br/cgi/idb2006/a05.htm

Brasil - Ministério da Saúde. DATASUS. Internações hospitalares [Internet]. Brasília: DATASUS; 2004 [cited 2008 May 28]. Available from: http:// tabnet.datasus.gov.br/cgi/idb2006/matriz.htm 
Carvalho JAM, Garcia RA. The aging process in the Brazilian population: a demographic approach. Cad Saúde Públ. 2003; 19(3):725-33.

Casserly I, Topol E. Convergence of atherosclerosis and Alzheimer`s disease: inflammation cholesterol, and misfolded protein. Lancet. 2004; 363(9415):1139-46.

Chaimowicz F. A saúde dos idosos brasileiros às vésperas do século XXI: problemas projeções e alternativas. Rev Saúde Públ. 1997; 31 (2): 184-200.

Copeland JRM, Dewey ME, Griffith-Jones HM. A computerized psychiatric diagnostic system and case nomenclature for elderly subjects: GMS and AGECAT. Psychol Med. 1986; 16(1):89-99.

den Heijer T, Launer LJ, Prins ND, van Dijk EJ, Vermeer SE, Hofman A, et al. Association between blood pressure, white matter lesions, and atrophy of the medial temporal lobe. Neurology. 2005; 64(2):263-7.

Desmond DW, Moroney JT, Paik MC, Sano M, Mohr JP, Aboumatar $\mathrm{S}$, et al. Frequency and clinical determinants of dementia after isquemic stroke. Neurology. 2000; 54(5):1124-31.

Desmond DW, Moroney JT, Sano M, Stern Y, Merino JG. Incidence of dementia after isquemic stroke. Stroke. 2002; 33(6):2254-62.

Dewey ME, Copeland JR. Diagnosis of dementia from the history and aetiology schedule. Int J Geriatr Psychiatry. 2001; 16(9):912-17.

Dulli DA, Stanko H, Levine RL. Atrial fibrillation is associated with severe acute ischemic stroke. Neuroepidemiology. 2003; 22(2):118-23.

Elias PK, Elias MF, Robbins MA, Budge MM. Blood pressure-related cognitive decline: does age make a difference? Hypertension. 2004; 44(5):631-6.

EpiCalc2000 - Brixton Health - 2000. Disponivel em:

http://www.brixtonhealth.com/epicalc.html

EpiData Association, Odense Denmark 2002. (v3.0). Versão para o português(Brasil) por João Paulo Amaral Haddad. Disponivel em: http://www.epidata.dk

Estes NAM, Halperin JL, Calkins H, Ezekowitz MD, Gitman P, Go AS, et al. ACC/AHA/Physician Consortium 2008 Clinical Performance Measures for Adults With Nonvalvular Atrial Fibrillation or Atrial Flutter: A Report of the American College of Cardiology/American Heart Association Task Force on Performance Measures and the Physician Consortium for Performance Improvement (Writing 
Committee to Develop Clinical Performance Measures for Atrial Fibrillation). Circulation. 2008; 117(8); 1101-20.

Eriksson P, Hansson PO, Eriksson H, Dellborg M. Bundle-Branch Block in a general male population: the study of men born 1913 . Circulation. 1998; 98(22):2494-500.

Eriksson P, Wilhelmsen L, Rosengren A. Bundle-branch block in middle-aged men: risk of complications and death over 28 years: The Primary Prevention Study in Göteborg, Sweden. Eur. Heart J.2005; 26(21):2300-2306.

Feinberg WM, Blackshear JL, Laupacis A, Kronmal R, Hart RG. Prevalence, age distribution and gender of patients with atrial fibrillation. Analysis and implications. Arch Intern Med. 1995; 155 (5): 469-73.

Ezekowitz MD, James KE, Nazarian SM, Davenport J, Broderick JP, Gupta SR, et al. Silent cerebral infarction in patients with nonrheumatic atrial fibrillation. the veterans affairs stroke prevention in nonrheumatic atrial fibrillation investigators. Circulation. 1995; 92(8): 2178-82.

Ferri CP, Prince M, Brayne C, Brodaty H, Fratiglioni L, Ganguli M, et al. Global prevalence of dementia: a Delphi consensus study. Lancet. 2005; 366(9503): 2112-7.

Freitag MH, Peila R, Masaki K, Petrovitch H, Ross GB, White LR, et al. Midlife pulse pressure and incidence of dementia: the HonoluluAsia Aging Study. Stroke. 2006; 37(1):33-7.

Freitas OC, Carvalho FR, Neves JM, Veludo PK, Parreira RS, Gonçalves RM, et al. Prevalence of Hypertension in the Urban Population of Catanduva, in the State of São Paulo, Brazil. Arq Bras Cardiol. 2001; 77(1):16-21.

Friedwald WT, Levy RI, Fredrickson DS. Estimation of the concentration of low-density lipoprotein cholesterol in plasma, without use of the preparative ultracentrifuge. Clin Chem 1972; $18(6): 499-502$.

Fuentes $\mathrm{R}$, Ilmaniemi $\mathrm{N}$, Laurikainen $\mathrm{E}$, Tuomilehto $\mathrm{J}$, Nissinen A. Hypertension in developing economies: a review of population-based studies carried out from 1980 to 1998. J Hypertens. 2000; 18(5):5219.

Fuster V, Ryd' en LE, Asinger RW, Cannom DS,Crijns HJ, Curtis AB, et al. ACC/AHA/ESC guidelines for the management of patients with atrial fibrillation- Executive Summary. A Report of the American College of Cardiology/American Heart Association Task Force on 
Practice Guidelines and the European Society of Cardiology Committee for Practice Guidelines (Writing Committee to Revise the 2001. Guidelines for the Management of Patients With Atrial Fibrillation). Developed in Collaboration With the European Heart Rhythm Association and the Heart Rhythm Society. J Am Coll Cardiol. 2006; 48(4):854-906.

Gage BF, Waterman AD, Shannon W, Boechler M, Rich MW, Radford MJ. Validation of clinical classification schemes for predicting stroke. Results from the national registry of atrial fibrillation. JAMA. 2001; 285(22):2864-70.

Go AS, Hylek EM, Phillips KA, Chang YC, Renault LE, Selby JV, et al. Prevalence of diagnosed atrial fibrillation in adults: national implications for rhythm management and stroke prevention: the AnTicoagulation and Risk Factors in Atrial Fibrillation (ATRIA) Study. JAMA. 2001; 285(18):2370-5.

Go AS. The epidemiology of atrial fibrillation in the elderly persons: the tip of the iceberg. Am J Geriatr Cardiol. 2005; 14(2):56-61.

Goldenberg P, Schenkman S, Franco LJ. Prevalência de diabetes mellitus: diferenças de gênero e igualdade entre os sexos. Rev Bras Epidemiol. 2003;6(1):18-28.

Grigioni F, Barbieri A, Magnani G, potena L, Coccolo F, Boriani G. Serial versus isolated assessment of clinical and instrumental parameters in heart failure: prognostic and therapeutic implications. Am Heart J. 2003; 146(2):298-303.

Grundy SM. Metabolic Syndrome Pandemic. Arterioscler Thromb Vasc Biol. 2008; 28(4):629-36. Hall KS, Hendrie HH, Brittain HM, Norton JA, Rodgers DD. The development of a dementia interview in two distinct languages. Int J Methods Psychiatr Res. 1993; 3(1): 1-28.

Hall KS, Gao S, Emsley XL, Ogunniyi AO, Morgan O, Hendrie HC. Community screening interview for dementia (CSI -D); performance in five disparate study sites. Int $J$ Geriatr Psychiatr. 2000; 15(6):52131 .

Hankey GJ, Sudlow CL, Dunbabin DW. Thienopyridine derivatives (ticlopidine, clopidogrel) versus aspirin for preventing stroke and other serious vascular events in high vascular risk patients. Cochrane Database Syst Rev. 2000;(2):CD001246.

Hardarson T, Árnason A, Eliasson GL, Pálsson K, Eyjólfsson K, Sigfusson N. Left bundle branch block: prevalence, incidence, followup and outcome. Eur Heart J. 1987 8(10):1075-9. 
Hart RG. Atrial fibrillation and stroke prevention. N Engl J Med. 2003; 349(11):1015-6.

Heeringa J, Van der Kuip DAM, Hofman A, Kors JA, Van Herpen G, Stricker BHC, et al. Prevalence, incidence and lifetime risk of atrial fibrillation: the Rotterdam Study. Eur Heart J. 2006; 27(8):949-53.

Herrera E Jr, Caramelli P, Silveira AS, Nitrini R. Epidemiologic survey of dementia in a community-dwelling brazilian population. Alzheim Dis Ass Disord. 2002; 16(2):103-8.

Hylek EM, Go AS, Chang Y, Jensvold NG, Henault LE, Selby JV, et al. Effect of Intensity of Oral Anticoagulation on Stroke Severity and Mortality in Atrial Fibrillation. New Engl J Med. 2003; 349(11):101926.

IBGE - Instituto Brasileiro de Geografia e Estatística. Pesquisa de Orçamentos Familiares - POF 2002-2003. Análise da disponibilidade domiciliar de alimentos e do estado nutricional no Brasil: estado nutricional, precisão das estimativas e totais da população; tabela 6 [Internet]. Rio de Janeiro: IBGE; 2008 [cited 2008 May 28]. Disponivel em:

http://www.ibge.gov.br/home/estatistica/populacao/condicaodevida /pof/2002analise/defaulttab.shtm

Israel CW, Gronefeld G, Ehrlich JR, Li Y, Hohnloser SH. Long-term risk of recurrent atrial fibrillation as documented by an implantable monitoring device. Implications for optimal patient care. J Am Coll Cardiol. 2004; 43(1):47-52.

Ivan CS, Seshadri S, Beiser A, Au R, Kase CS, Kelley-Hayes M, et al. Dementia After Stroke- The Framingham Study. Stroke. 2004; 35(6):1264-9.

Jorgesen HS, Nakayama H, Reith J,Raaschou HO, Olsen TS. Acute stroke with atrial fibrillation: the Copenhagen Stroke Study. Stroke. 1996; 27(10):1765-9.

Kelley-Hayes M, Beiser A, Kase CS, Scaramucci A, D'Agostinho $\mathrm{RB}$, Wolf PA. The influence of gender and age on disability following ischemic stroke: the Framingham study. J Stroke Cerebrovasc Dis. 2003; 12(3):119-26.

Lamassa M, Carlo A, Pracucci G, Basile AM, Trefoloni G, Vanni P, et al. Characteristics, Outcome, and Care of Stroke Associated With Atrial Fibrillation in Europe. Stroke. 2001; 32(2):392-8.

Lessa I, Conceição JL,Souza ML, Oliveira V,Carneiro J, Melo J, et al. Prevalência de dislipidemia em adultos da demanda laboratorial de Salvador, Brasil. Arq Bras Cardiol .1997; 69 (6):395-400. 
Li G, Higdon R, Kukull WA, Peskind E, Moore KV, Tsuang D, et al. Statin therapy and risk of dementia in the elderly: a communitybased prospective cohort study. Neurology 2004; 63(9):1624-8.

Lloyd-Jones DM, Wang TJ, Leip EP, Larson MG, Levy D; Vasan R, et al. Lifetime risk for development of atrial fibrillation: the Framingham Heart Study. Circulation. 2004; 110(9):1042-6.

Lopes MA, Bottino CMC. Prevalência de demência em diversas regiões do mundo. Análise dos estudos epidemiológicos de 1994 a 2000. Arq Neuro-Psiquiatr. 2002; 60(1):61-9.

Lolio Ca, Souza JMP, Laurenti R. Decline in cardiovascular disease mortality in the city of S. Paulo, Brazil, 1970 to 1983. Rev. Saúde Publ. 1986; 20(6): 454-64.

Lotufo PA. Increasing obesity in Brazil: predicting a new peak of cardiovascular mortality. São Paulo Med J. 2000; 118(6):161-2.

Lotufo PA. Stroke in Brazil: a neglected disease. Sao Paulo Med J. 2005b; 123(1):3-4.

Lotufo PA. Why Brazil does not have an epidemic of chronic diseases: some answers from cardiovascular diseases. Sao Paulo Med J. 2005a; 123(2):47-8.

Lotufo PA, Goulart AC, Bensenor IM. Race, gender and stroke subtypes mortality in São Paulo, Brazil. Arq Neuropsychiatr. 2007; 65 (3-B): 752-7.

Manolio TA, Furberg CD, Rautahaniu PM, Siscovick D, Newman AB, Borhani NO, et al. Cardiac arrhythmias on 24-h ambulatory electrocardiography in older women and men: the Cardiovascular Health Study. J Am Coll Cardiol. 1994; 23(4):916-25.

McKeith IG, Perry RH, Fairbairn AF, Jabeen S, Perry EK, et al. Operational criteria for senile dementia of Lewy body type (SDLT). Psychol Med. 1992; 22(4):911-22.

McKhann G, Drachman D, Folstein M, Katzman R, Price D, Stadlan EM. Clinical diagnosis of Alzheimer's disease: report of the NINCDSADRDA Work Group under the auspices of Department of Health and Human Services Task Force on Alzheimer's Disease. Neurology. 1984; 34(7): 939-44.

Meguro K, Meguro M, Caramelli P, Ishizaki J, Ambo H, Chubaci RYS, et al. Elderly Japanese emigrants to Brazil before World War II: II. Prevalence of senile dementia. Int J Geriatr Psychiatry. 2001; 16(8): 775-9. 
Miller WL; Ballman KV,Hodge DO, Rodeheffer RJ, Hammill SC. Risk factor implications of incidentally discovered uncomplicated bundle branch block. Mayo Clin Proc. 2005; 80(12):1585-90.

Miyasaka Y, Barnes ME, Gersh BJ, Cha SS, Seward JB, Bailey KR, et al. Risk of dementia in stroke-free patients diagnosed with atrial fibrillation: data from a community-based cohort. Eur Heart J. 2007; 28(16):1962-7.

National Diabetes Statistics, 2005. [cited 2008 May 28]. Available from:

http://diabetes.niddk.nih.gov/dm/pubs/statistics/\#9

Newman AB, Fritzpatrick AL, Lopez O, Jackson S, Lyketsos C, Jagust $\mathrm{W}$, et al. Dementia and Alzheimer's disease incidence in relationship to cardiovascular disease in the Cardiovascular Health Study cohort. J Am Geriatr Soc. 2005; 53(7): 1101-7.

Nitrini R, Caramelli P, Herrera E Jr, Bahia VS, Caixeta LF, Radanovic $\mathrm{M}$, et al. Incidence of dementia in a community-dwelling Brazilian population. Alzheimer Dis Assoc Disord. 2004;18(4):241-6.

Nitrini R, Caramelli P, Herrera E Jr, Castro I, Bahia VS, Anghinah R, et al. Mortality from dementia in a community-dwelling Brazilian population. Int J Geriatr Psychiatry. 2005; 20(3): 247-53.

Oliveira JE, Milech A, Franco LJ. The prevalence of diabetes in Rio de Janeiro, Brazil. Diabetes Care 1996; 19(6):663-6.

Ott A, Breteler M, de Bruyne M, Harskamp F, Grobbee DE, Hofman A. Atrial fibrillation and dementia in a population-based study: the Rotterdam Study. Stroke.1997; 28(10):316-21.

Page RL, Wilkinson WE, Clair WK, Carsten WI, Grpnefeld G, Ehrlich $\mathrm{JR}$, et al. Asyntomatic arrhytmias in patients with syntomatic paroxysmal atrial fibrillation and paroxysmal supraventricular tachycardia. Circulation. 1994; 89(1): 224-7.

Park H, Hildreth A, Thomson R, O'Connell J. Non-valvular atrial fibrillation and cognitive decline: a longitudinal cohort study. Age Ageing. 2007; 36(2):157-63.

Peixoto SV, Giatti L, Afradique ME, Lima-Costa MF. Custo das internações hospitalares entre idosos brasileiros no âmbito do Sistema Único de Saúde. Epidemiologia e Serviços de Saúde 2004; 13(4): $239-46$.

Penado S, Cano M, Acha O, Hernández JL, Riancho JA. Atrial fibrillation as a risk factor for stroke recurrence. Am J Med. 2003; 114(3): 206-10. 
Pereira MR, Coutinho MSSA, Freias PF, D'Orsi E, Bernardi A, Hass, R. Prevalência, conhecimento, tratamento e controle de hipertensão arterial sistêmica na população adulta urbana de Tubarão, Santa Catarina, Brasil, em 2003. Cad Saúde Públ. 2007; 23 (10): 2363-74.

Piccini RX, Victora CG. Hipertensão arterial sistêmica em área urbana no sul do Brasil: prevalência e fatores de risco. Rev. Saúde Públ. 1994; 28(4):261-7.

Prince M, Acosta D, Chiu H, Scazufca M, Varghese M. 10/66 $\mathrm{F} \backslash$ Dementia Research Group. Dementia diagnosis in developing countries: a cross-cultural validation study. Lancet. 2003; 361(9361): 900-17.

Prineas R, Crow R, Blackburn H. Minnesota Code Manual of Electrocardiographic Findings. John Wright-PSG, InNc

Purandare N, Burns A, Daly KJ, Hardicre J, Morris J, Macfarlane G, et al. Cerebral emboli as a potential cause of Alzheimer's disease and vascular dementia: case-control study. BMJ 2006;332(7550);11191124.

Ramos-Cerqueira ATA, Torres AR, Crepaldi AL, Oliveira NIL, Scazufca $\mathrm{M}$, Menenzes $\mathrm{P}$, et al. Identification of dementia cases in the community: a brazilian experience. $J$ Am Geriatr Soc. 2005; 53(10):1738-42.

Rea T, Breitner J, Psaty BM, Fritzpatrick AL, Lopez OL, Newman AB, et al. Statin use and the risk of dementia. Arch Neurology 2005;62(7):1047-51.

Ramos LR, Veras RP, Kalache A. Envelhecimento populacional: uma realidade brasileira. Rev Saúde Publ. 1987; 21(30):211-24.

Rash R, Downes T, Portner R, Yeo WW, Morgan N, Channer KS. A randomised controlled trial of warfarin versus aspirin in octogenarians with atrial fibrillation (WASPO). Age Ageing. 2007; 36(2):151-6.

Regan C, Katona C, Walker Z, J Hooper, J Donovan, Livingston G. Relationship of vascular risk to the progression of Alzheimer disease. Neurology. 2006; 67(8):1357-62.

Roman GC, Tatemichi TK, Erkinjuntti T, Cummings JL, Masdeu JC, Garcia JH, et al. Vascular dementia: Diagnostic criteria for research studies. Report of the NINDS-AIREN International Workshop. Neurology. 1993; 43(2):250-60.

Rosamond W, Flegal K, Furie K, Go A, Greenlund K, Haase N, et al. Heart Disease and Stroke Statistics 2008 Update: A Report From the 
American Heart Association Statistics Committee and Stroke Statistics Subcommittee. Circulation 2008;117(4);e25-e146.

Sabatini T, Frisoni GB, Barbisoni P, Bellelli G, Rozzini R, Trabucchi M. Atrial fibrillation and cognitive disorders in older people. $J \mathrm{Am}$ Geriatr Soc. 2000; 48(4):387-90.

Scazufca M, Cerqueira A, Menezes PR, Prince M, Vallada HP, Myasaki MCOS, et al. Investigações epidemiológicas sobre demência nos países em desenvolvimento. Rev Saúde Publ. 2002; 36(6): 773-8.

Scazufca M, Seabra CAF. São Paulo portraits: ageing in a large metropolis. Int $J$ Epidemiol advanced access published July 31, 2007.

Scazufca M, Menezes PR, Vallada HP, Crepaldi AL, Pastor-Valero M, Coutinho LMS, et al. High prevalence of dementia among old adults from poor socioeconomic backgrounds in São Paulo, Brazil. Int Psychoger. 2008; 20(2): 394-405.

Schneider JF, Thomas HE Jr, Sorlie P, Kreger BE, McNamara PM, Kannel WB. Comparative features of newly adquired left and right bundle-branch block in the general population: the Framingham study. Am J Cardiol. 1981; 47(4):931-40.

Schneider JF, Thomas HE Jr, Kreger BE, McNamara PM, Kannel WB. Newly acquired left bundle-branch block. The Framingham Study. Ann Intern Med. 1979; 90(3):303-10.

Shurtleff D. Some characteristics related to the incidence of cardiovascular disease and death: Framingham study, 18 year followup. In: Kannel WB, Gordon T, editors. The Framingham study: an epidemiological investigation of cardiovascular disease. Washington: Government Printing Office; 1974. (DHEW publication no. [NIH] 74599).

Silvestrini M, Pasqualetti P, Baruffaldi R, Bartolini M, Handouk Y, Matteis $\mathrm{M}$, et al. Cerebrovascular reactivity and cognitive decline in patients with Alzheimer disease. Stroke 2006; 37(4): 1010-5.

Souza LJ, Souto Filho JTD, Souza TF, Reis AFF, Gicovate Neto C, Bastos DA, et al. Prevalence of dyslipidemia and risk factors in Campos dos Goytacazes, in the Brazilian State of Rio de Janeiro. Arq. Bras Cardiol. 2003a; 81(3): 257-64.

Souza LJ, Gicovate Neto C, Chalita FEB, Reis AFF, Bastos DA, Souto Filho JT, et al. Prevalência de Obesidade e Fatores de Risco Cardiovascular em Campos, Rio de Janeiro. Arq Bras Endocrinol Metab. 2003b;47(6):669-76. 
Sparks PB, Kalman JM. Is atrial flutter risk for stroke? $J$ Am Coll Cardiol. 2001; 38(3):785-8.

Stata 8.0 . Stata Statistical Software, Release 8. College Station, TX: StataCorp.

Stat/Transfer - version - 32 bits Windows - Circle System, Inc. http://www.stattransfer.com/html/win__mac_download.html

Stewart R, Prince M, Mann A. Vascular risk factors and Alzheimer's disease. Aust New Zeal J Psychiatr. 1999; 33(6):809-13.

Tatemichi TK, Desmond DW, Stern Y, Paik M, Sano M, Bagiella E. Cognitive impairment after stroke: frequency, patterns, and relationship to functional abilities. $J$ Neurol Neurosurg Psychiatry. 1994; 57(2): 202-7.

Torquato MTCG, Montenegro Junior RM, Viana LAL, Souza RAHG, Lanna CMM, Lucas JCB, et al. Prevalence of diabetes mellitus and impaired glucose tolerance in the urban population aged 30-69 years in Ribeirão Preto (São Paulo), Brazil. Sao Paulo Med J. 2003; 121(6): 224-30.

Trindade IS, Heineck G, Machado JR, Ayzemberg H, Formighieri M, Crestani $\mathrm{M}$, et al. Prevalência da hipertensão arterial sistêmica na população urbana de Passo Fundo (RS). Arq Bras Cardiol. 1998; 71(2):127-30.

United Nations. Department of Economic and Social Affairs. World population Prospects. World Population Ageing 2007 [Internet]. New York: DESA; 2007a [cited 2008 May 28]. Available from: www.un.org/esa/population/unpop.htm

United Nations. Department of Economic and Social Affairs. Population Division. World population prospects. The 2006 revision [Internet]. New York: DESA; 2007b [cited 2008 May 28]. Available from:

http:/ /www.un.org/esa/population/publications/wpp2006/wpp200 6_ageing.pdf

United Nations. América Latina: Fecundidad 1950-2050 [periódico online]. Boletín Demográfico. 2001a [cited 2008 May 28];34(68):[131 p.]. Disponible en:

http: / / www.eclac.cl/cgi-

bin/getProd.asp?xml=/publicaciones /xml/3/7463/P7463.xml\&xsl= / celade $/ \mathrm{tpl} / \mathrm{p} 9$ f.xsl\&base $=/$ celade $/ \mathrm{tpl} /$ top-bottom.$x$ slt

United Nations. Department of Economic and Social Affairs. Population Division. World population ageing 1950-2050. New York: DESA; $2001 b$. 
http://www.un.org/esa/population/publications/worldageing19502 050/pdf/preface_web.pdf

Veermer SE, Prins ND, Heijer T, Hofman A, Koudstaal PJ, Breteler, M. Silent Brain Infarcts and the Risk of Dementia and Cognitive Decline. New Engl J Med. 2003; 348(13):1215-22.

Vitelli LL, Crow RS, Sharar E, Hutchinson RG, Rautaharju PM, Folsom AR. Eletrocardiographic findings in a health biracial population. Atherosclerosis risk in communities (ARIC) Study Investigators. Am J Cardiol.1998; 81(4):453-9.

V JNC - The fifth report of the Joint National Committee on the Detection, Evaluation, and Treatment of Blood Pressure. Arch Intern Med. 1993; 153(2):154 -83.

Wattigney WA, Mensah GA, Croft JB. Increased atrial fibrillation mortality: United States, 1980-1998. Am J Epidemiol. 2002; 155(9):819-26.

Welsh KA, Butters N, Mohs RC, Beekly D, Edland S, Fillenbaum G, et al. The Consortium to Establish a Registry for Alzheimer's Disease (CERAD). Part V. A normative study of the neuropsycological battery. Neurology. 1994; 44(4):609-14.

Wild S, Roglic G, Green A, Sicree R, King H. Global Prevalence of Diabetes: Estimates for the year 2000 and projections for 2030. Diabetes Care. 2004; 27(5):1047-53.

Wimo A, Winblad B, Jönsson L. An estimate of the total worldwide societal costs of dementia in 2005. Alzheimer's \& Dementia. 2007; 3(2): 81-91

Wolf PA, Abbott RD, Kannel WD. Atrial fibrillation as an independent risk factor for stroke: the Framingham study. Stroke.1991; 22(8):9838.

World Health Organization. Department of Noncommunicable Diseases Prevention and Health Promotion. Noncommunicable Diseases and Mental Health Cluster. Life course perspectives on coronary heart disease, stroke and diabetes: key issues and implications for policy and research [Internet]. Geneva: WHO; 2001 [cited 2008 May 28]. Summary report of a meeting of experts, 2-4 May, 2001. Available from:

http://whqlibdoc.who.int/hq/2001/WHO_NMH_NPH_01.4.pdf

World Health Organization. Obesity and overweight; September, 2006 [Internet]. Geneva: WHO; 2008 [cited 2008 May 28]. Available from: http://www.who.int/mediacentre/factsheets/fs311/en/print.html 
Yamada T, Kadekaru H, Matsumoto S, Inada H, Tanabe M, Moriguchi $\mathrm{EH}$, et al. Prevalence of dementia in the older Japanese-Brazilian population. Psychiatry Clin Neurosci. 2002; 56(1):71-5.

Zamrini E, McGwin G, Roseman JM. Association between statin use and Alzheimers disease. Neuroepidemiology. 2004; 23(1-2):94-8.

Zaitune MPM, Barros MBA, César CLG, Corandina L, Goldbaum M. Hipertensão arterial em idosos: prevalência, fatores associados e práticas de controle no Município de Campinas, São Paulo, Brasil. Cad Saúde Públ. 2006; 22(2):285-294.

*De acordo com:

Adaptado de International Committee of Medical Journals Editors (Vancouver)

Universidade de São Paulo. Faculdade de Medicina. Serviço de Biblioteca e Documantação. Guia de apresentação de dissertações, teses e monografias. Elaborado por Anneliese Carneiro da Cunha, Mria Julia de A. L. Freddi, Maria F. Crestana, Marinalva de Souza Aragão, Suely Campos Cardoso, Valéria Vilhena. São Paulo: Serviço de Biblioteca e Documentação; 2005.

Abreviaturas dos títulos dos periódicos de acordo com List of Journals Indexed in Index Medicus. 
Apêndices 